\title{
Constitutive Models for Fibre Reinforced Soil Bricks
}

\author{
Mahgoub M. Salih, Adelaja I. Osofero*, and Mohammed S. Imbabi
}

School of Engineering, University of Aberdeen, United Kingdom

*Corresponding Author: aiosofero@abdn.ac.uk+44 (0) 1224274255

\section{ABSTRACT}

In this paper, the physical, durability and mechanical properties of soil bricks reinforced with chicken feather fibres (CFF) and sugarcane bagasse fibres (SBF) were studied. The adopted optimum lengths of $15-\mathrm{mm}$ of CFF and SBF were randomly distributed in the soil mix at $1 \%$, $3 \%, 5 \%, 7 \%, 9 \%$ and $11 \%$ by weight. In total, 525 samples of cubic (350) and prismatic (175) soil samples were prepared for each fibre type and tested in accordance with the guidance in the British standards for bulk density, water absorption, compressive strength and tensile strength at 14, 28, 56, 90 and 180 days. With the addition of $7 \%$ CFF and 5\% SBF, soil brick samples were found to be $98.8 \%$ and $78.7 \%$ stronger respectively in compression compared to the control mix. Based on the experimental results the stress-strain model describing the soil bricks response to compressive loading for each fibre type was obtained via regression analysis. This study contributes original data to the characterization of soil bricks and provides reference values that can be considered for design purposes. The soil bricks thus developed will contribute to the provision of affordable and sustainable housing construction across the world, particularly in developing countries.

\section{Keywords:}

Soil bricks; Mechanical characterization; Constitutive models; Stress-strain curves; Sustainable construction material; SEM; XRD; Compression test results. 


\section{Introduction}

Soil bricks have been used since ancient times. Their first recorded use dates back to 10,000 BC in Mesopotamia where it was used in the construction of houses and other buildings [1]. Soil bricks have been used widely for wall construction across the world and continues today in developing countries. Coffman et al. [2] stated that about $30 \%$ of the global population still live in earthen structures. This has been attributed to their simplicity, material availability, easy repair and maintenance, minimal impact on the environment and lower cost compared to modern construction materials such as concrete and steel. However, the main weaknesses of soil bricks are their susceptibility to water damage and low compressive and tensile strength properties. The purpose of adding waste additives, obtained from plants and animals, to the soil mix is to improve the mechanical properties of the bricks by creating a network of fibres, which reduce shrinkage and improves strength as well as stiffness.

Large quantities of natural wastes are generated from production and manufacturing processes, which raise significant environmental and sustainable concerns. Reuse of these wastes in brickmaking has attracted a great deal of interest in recent years [3-7]. The use of waste fibres is beneficial, especially if the fibres are locally available in abundance, cost-effective, consume low energy and impose minimal environmental impacts.

Many fibres have been investigated to enhance the properties of soil bricks. The studies in this area mainly focused on the improvement of compressive and tensile strength [8-15]. These studies showed that reinforcement of soil bricks with waste fibres often improved some mechanical properties. In general, the compressive and tensile strength of reinforced soil bricks in the literature vary between $0.60-5.00$ and $0.16-3.10 \mathrm{MPa}$ respectively [8-10]. Higher compressive and tensile strength is obtained when fibre reinforced soil bricks are stabilised 
with cement [11-13] and/or lime [14, 12]. In case of waste tea fibres, complete drying via oven is required [15].

There are only two reported studies on the use of animal fibres in reinforcing soil bricks [7, 16]. This type of fibre, therefore, requires more attention. Chicken feathers, for example, are an abundant animal fibre globally - see Figure 1a. About 4 million tons of chicken feathers are produced as agricultural waste annually worldwide [17]. Chicken feathers are inexpensive and lightweight with excellent compressibility and resilience. Due to these desirable characteristics, a number of studies have investigated the use of fibres obtained from chicken feathers in potential industrial applications such as in textile industry [18], bioplastics [19], and wastewater treatment [20]. Recently, the use of chicken feather fibres (Barb) in reinforcing soil bricks has been proposed by Salih et al. [21].

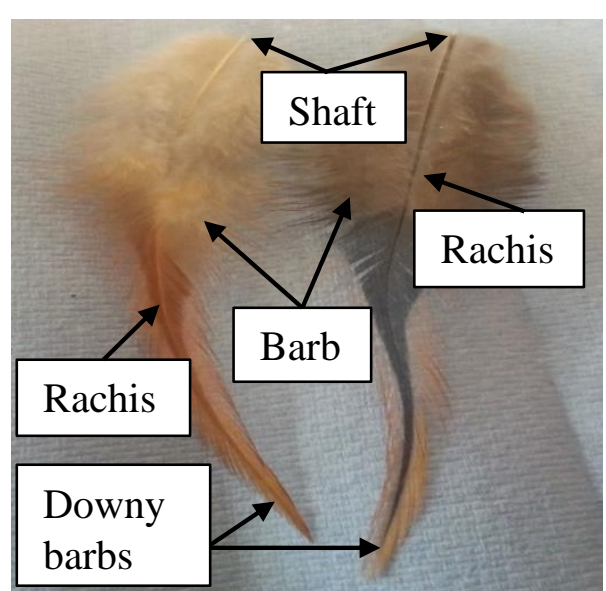

(a)

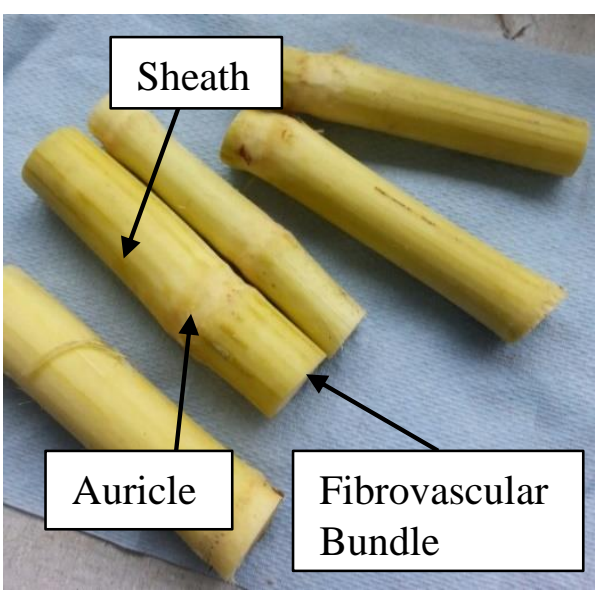

(b)

Figure 1: Annotated diagram of (a) chicken feathers and (b) sugarcane bagasse.

Another abundant fibre in many parts of the world is sugarcane bagasse (Figure 1b). The annual production of sugarcane bagasse globally is over 54 million tons [22]. This large amount of sugarcane bagasse waste creates several environmental problems such as land contamination, dust and air pollution [23]. Recently, the inclusion of this waste in clay bricks has been proposed by Vieira et al. [24] and Teixeira et al. [25]. In addition, Bock-Hyeng et al. [8] 
examined the performance of earth bricks with sugarcane bagasse as an additive. The results indicated that the addition of this fibre led to an improvement in strength, durability and stability. However, the results from these studies are limited to low percentage content of sugarcane bagasse fibre.

An important objective of the present study has been to investigate the properties of soil bricks reinforced using two types of waste fibre, chicken feather fibre (CFF) and sugarcane bagasse fibre (SBF). To achieve this, the physical, durability and mechanical properties of the fibre reinforced soil bricks were studied. The study thus reports the results of an exhaustive experimental investigation by the authors of natural fibre reinforced soil bricks at 14, 28, 56, 90 and 180 days.

This work contributes to the application of soil bricks in construction. It will contribute to efforts geared towards meeting the increasing demand for housing, as populations increase in a sustainable manner. The paper is relevant to researchers in the field of sustainable construction material development, including civil and construction engineers as well as contractors, with particular relevance to those working in developing countries. The paper will also have significant impact on all researchers involved in the development of alternative construction material globally.

\section{Materials and methods}

\subsection{Raw materials}

The constituent materials used in this research include soil, chicken feather fibres (CFF) and sugarcane bagasse fibres (SBF) (Figure 2). Soil is locally available in abundance which makes it affordable and easy to obtain. The soil used in this study was supplied by Jewson brick company Ltd (United Kingdom) and is currently used by brick manufacturers to make unfired soil bricks. The main characteristics of the soil used are summarised in Table 1. 
96

97 98

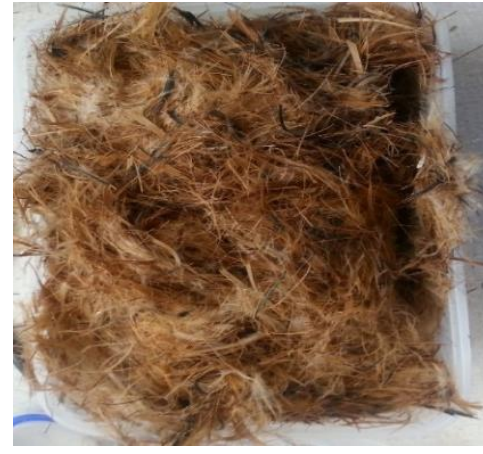

(b)

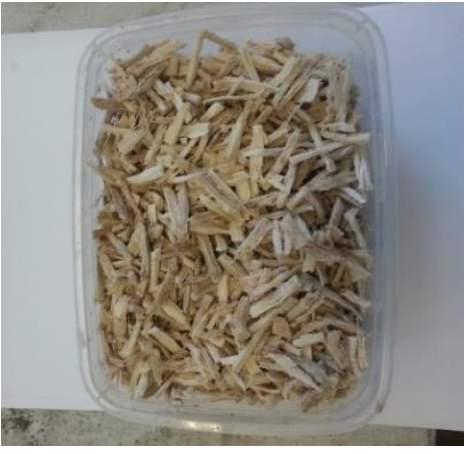

(c)

Figure 2: (a) Soil, (b) chicken feather fibres (CFF), (c) sugarcane bagasse fibres (SBF).

Table 1: Properties of selected soil.

\begin{tabular}{l} 
Property \\
\hline Optimum moisture content
\end{tabular}

Maximum dry density

Specific gravity

pH Value

Electrical conductivity

Colour

Classification as per AASHTO Soil Classification System [26]

\section{Composition}

$18.6 \%$

$1681 \mathrm{~kg} / \mathrm{m}^{3}$

Low

Grey

A-1

99

The CFF and SBF used in this work were left to dry naturally at room temperature until constant weight was achieved. The fibres were trimmed off with a scissor to four different fibre lengths;

$5,10,15$ and $20 \mathrm{~mm}$ and randomly included in the specimens. CFF and SBF were of an average diameter of 15 and $40 \mu \mathrm{m}$ respectively. Some of the properties of these fibres were summarized in Table 2. 
Table 2: Physical properties of fibres.

\begin{tabular}{cccccc}
\hline Fibre & $\begin{array}{c}\text { Optimum } \\
\text { length }(\mathbf{m m})\end{array}$ & $\begin{array}{c}\text { Diameter } \\
(\boldsymbol{\mu m})\end{array}$ & $\begin{array}{c}\text { Aspect } \\
\text { ratio }\end{array}$ & $\begin{array}{c}\text { Density } \\
\left(\mathbf{g m} / \mathbf{c m}^{\mathbf{3}}\right)\end{array}$ & $\begin{array}{c}\text { Water absorption } \\
\text { \% (after 24 h) }\end{array}$ \\
\hline $\mathrm{CFF}$ & 15 & 15 & 0.001 & 0.07 & 0.68 \\
$\mathrm{SBF}$ & 15 & 40 & 0.004 & 0.13 & 0.79 \\
\hline
\end{tabular}

108

\subsubsection{Soil particle size distribution}

The soil was dried, and the particle size distribution determined by sieve analysis according to the guidance provided in ASTM D422-07 [26]. The soil consists of the following percentages by weight: $0 \%$ gravel (grain diameter $\mathrm{dg}>2.0 \mathrm{~mm}) ; 71.3 \%$ of sand $(0.063 \mathrm{~mm}<\mathrm{dg}<2.0 \mathrm{~mm})$ and $28.7 \%$ of silt and clay $(\mathrm{dg}<0.063 \mathrm{~mm})$. The Atterberg limits test was not performed as the clay fraction in the soil was too low. The particle size distribution is plotted in Figure 3.

Figure 3: Particle size distribution of the soil.

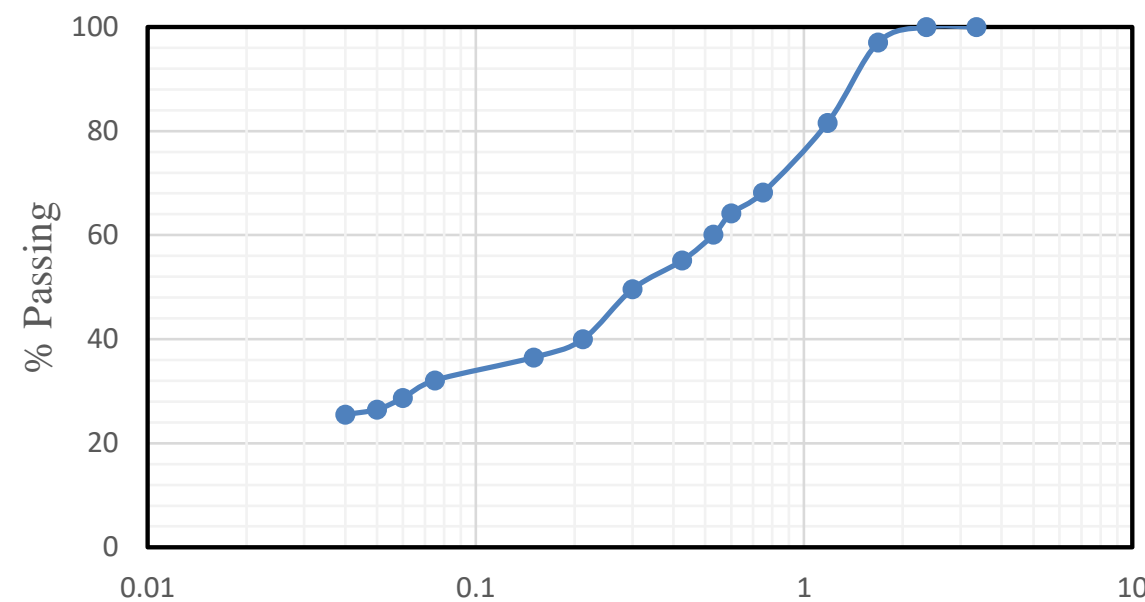

Particle diameter $(\mathrm{mm})$

Tensile testing was carried out on CFF and SBF, the fibre ends were dipped in Araldite epoxy glue to gain sufficient strength and assembled as shown in Figure 4. This technique was used 
to avoid damage of fibre ends in the region of the grips of the test machine. The tests are carried out after 72 hours, to ensure effective adhesion between glue/fibre. Hounsfield universal tester (Model H10KS) at displacement of $5 \mathrm{~mm} / \mathrm{mm}$ was used to determine the fibre tensile strength according to the guidance in ASTM D4761-13 [27].

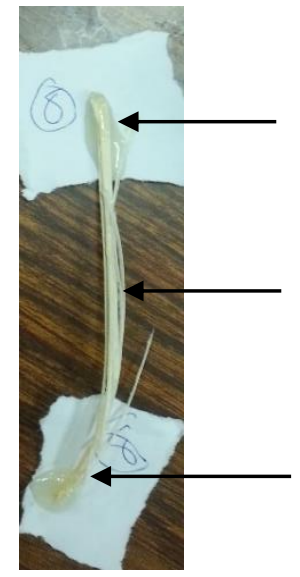

Epoxyglue bulb

SBF

Epoxyglue bulb

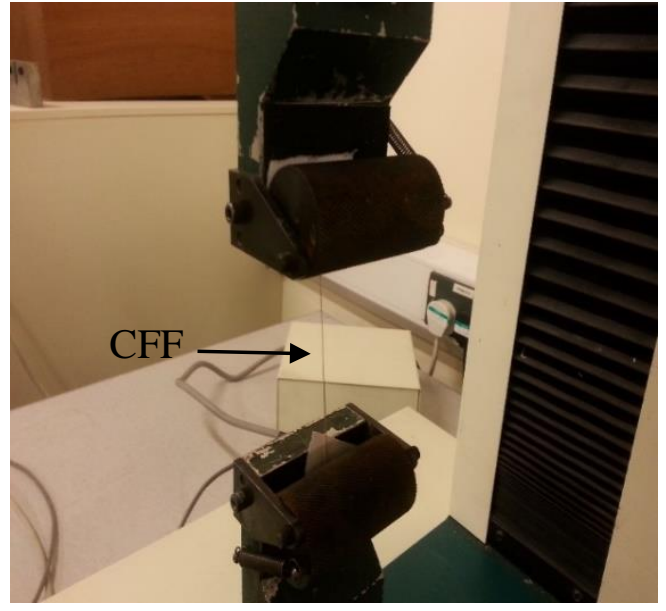

Figure 4: (a) SBF sample prepared for tensile test (b) CFF fixed in the tensile test equipment.

\subsubsection{XRD of raw materials}

The raw materials that were used were also analysed through the use of powder X-ray diffraction (XRD) for mineralogical characterization. The XRD apparatus used was a PANalytical X'Pert X-ray powder diffractometer equipped with monochromatic $\mathrm{Cu}-\mathrm{K}$ alpha radiation source. Powder specimens were analysed at room temperature and the test was carried out at $40 \mathrm{kV}$ and $30 \mathrm{~mA}$. A continuous mode was used for collecting data at room temperature in the $2 \theta$ range from $20^{\circ}$ to $80^{\circ}$ at a scanning speed of $8.5^{\circ} / \mathrm{min}$. The acquired data were identified using high score plus software to determine composition at each peak.

\subsubsection{SEM of raw materials}

For scanning electron microscopy (SEM) observations, a ZEISS GeminiSEM 300 Scanning Electron Microscope (SEM), fitted with a Solid-state Backscattered Detector (SBD), and linked with an Energy Dispersive X-ray (EDX) was used. This combination is capable of analysing electrons in the range of 10-100 atomic weights. 


\subsubsection{Preparation of specimens}

151 Three types of brick samples were prepared; soil samples with CFF, soil samples with SBF,

152 and control brick samples (without fibres). The nominal dimensions of specimens produced in steel moulds were $50 \mathrm{~mm} \times 50 \mathrm{~mm} \times 50 \mathrm{~mm}$ for compression tests and $40 \mathrm{~mm} \times 40 \mathrm{~mm} \times 160$ $\mathrm{mm}$ for three-point bending tests. The pouring and placement of the mix were carried out according to the guidance in British Standard EN 1052-2:2016 [28].

To ensure a uniform distribution of fibres within the soil mix and to avoid aggregation of the fibres throughout the mix, all the raw materials were batched, and dry mixing was carried out to distribute the fibres randomly within the soil matrix. The dry mix was then watered gradually in a uniform manner while mixing continued. The ingredients were then properly mixed for 5 minutes in an electric mixer until a homogenous mix was obtained. Moulds were lubricated on the inside to prevent sticking and fracturing of the newly formed samples.

Each mould was filled in three equal layers and each layer was compacted to its full depth. The compaction strokes were distributed in a uniform manner over the surface to ensure equal density (and thus stiffness) in the centre and corners of the mould. The excess soil was trimmed with a straightedge tool to make it level with the top of the mould (Figure 5).
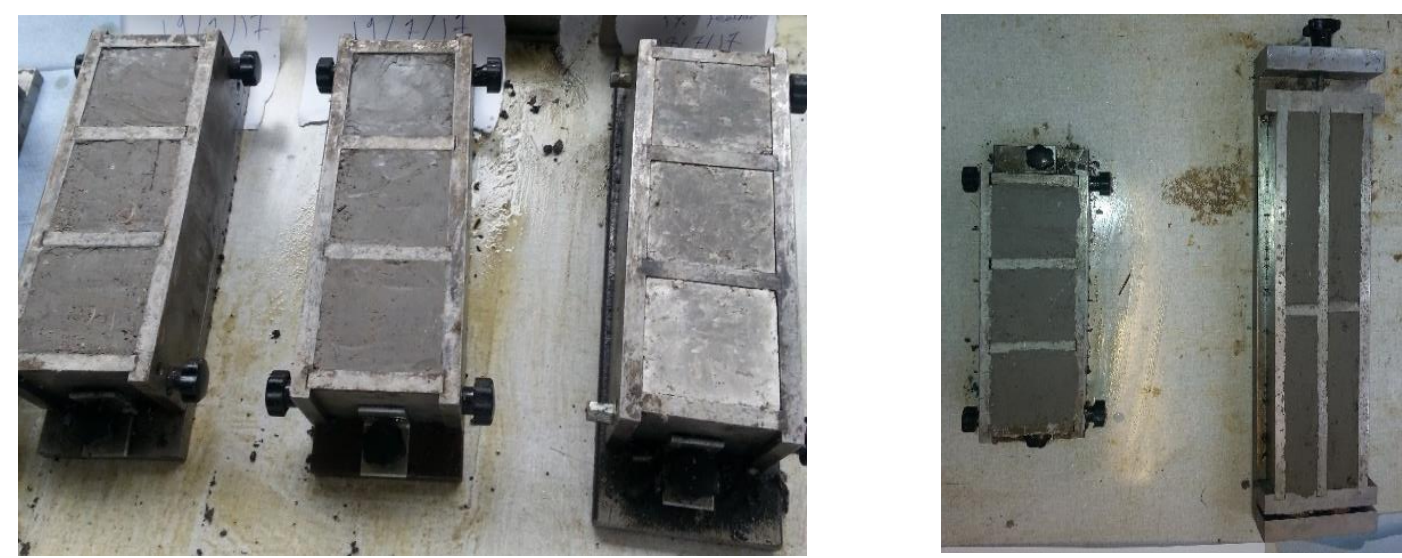

Figure 5: Brick samples at the time of casting. 
The specimens were then manually taken out of the mould carefully, and moist-cured at room temperature until a constant weight was achieved. Extrusion defects were not observed after drying. The fibre reinforced specimens were produced with chicken feather fibres (CFF) or sugarcane bagasse fibres (SBF) at $1 \%, 3 \%, 5 \%, 7 \%, 9 \%$ and $11 \%$ by weight as shown in Table 3. A total of five specimens for each mix were tested.

Table 3: Mix compositions of brick specimens.

\begin{tabular}{ccc}
\hline CFF/SBF fibre weight fraction $\left(\mathbf{W}_{\mathbf{f}}\right) \boldsymbol{\%}$ & Soil $(\mathbf{w t .} \%)$ & Water content \% \\
\hline 0 & 100 & 18.6 \\
1 & 99 & 18.6 \\
3 & 97 & 18.6 \\
5 & 95 & 18.6 \\
7 & 93 & 18.6 \\
9 & 91 & 18.6 \\
11 & 89 & 18.6 \\
\hline
\end{tabular}

\subsubsection{The test procedures}

The prepared specimens were tested for bulk density, water absorption, compressive strength and tensile strength at the end of the curing periods of 14, 28, 56, 90 and 180 days. According to the guidance in British Standard EN 1052-2:2016 [28], the properties of unreinforced soil bricks should be determined at 14 days or until constant weight is achieved. However, this study investigates beyond 14 days in order to evaluate any degradation effect of natural fibre

(CFF/SBF) with time. This is useful in establishing the behaviour of natural fibre reinforced soil bricks and assessing the safety of natural reinforced earth structure.

The density of the samples at the end of the curing period was determined and recorded according to guidelines in British Standard EN 772-13:2000 [29]. The density was calculated by dividing the dry mass by the average external volume. The density of construction materials 
is affected by the material constituents and method of production. It is associated with other brick properties such as compressive strength and water absorption.

The water absorption test was carried out to obtain the quantity of water absorbed by the samples and to establish the durability of soil bricks in a wet environment. Lower water absorption means lower water infiltration, hence higher durability when exposed to water [30].

The water absorption is determined from the moist weight of samples when submersion in a water bath for 24 hours after measuring their dry weight as per the British Standard EN 7711:2003 [31]. A total of 175 cubic specimens were tested for water absorption for each fibre type; (5 specimens for each of the 7 mix designs per fibre at 14, 28, 56, 90 and 180 days).

The compression test was conducted in accordance to the guidelines in British Standard EN 1052-2:2016 [28] to determine the compressive strength of the specimens. A total of 175 specimens were tested for compressive strength for each fibre type; (5 cubic specimens for peak compressive strength was calculated by dividing the failure load by the loading area.

202

203

204 with a maximum load capacity of $2000 \mathrm{KN}$ was used for the test (Figure 6). The rate of compression was set at $1.0 \mathrm{~mm} / \mathrm{min}$ until the sample failed. The failure load was recorded, and

Compressive load

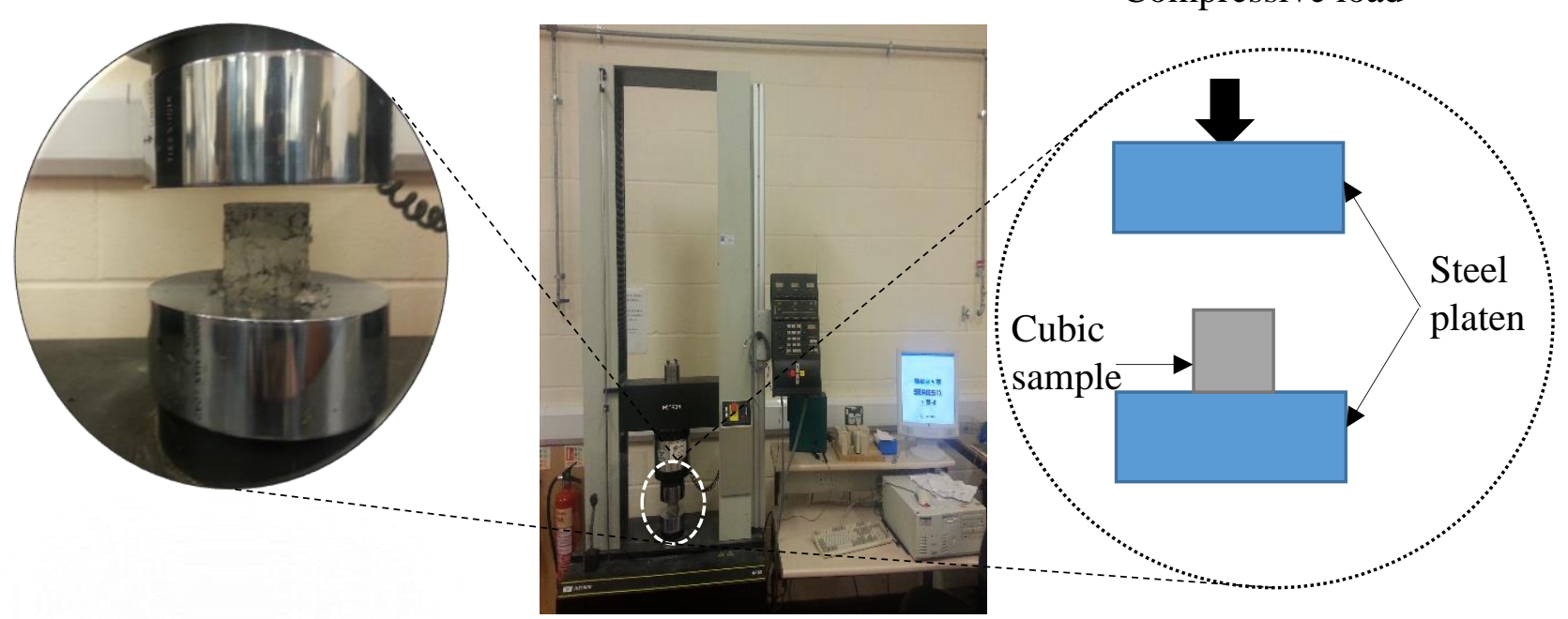

Figure 6: The experimental set-up for the compression test. 

to establish the flexural characteristics of the specimens. A total of 175 prismatic specimens were tested for bending tensile strength for each fibre type; (5 specimens for each of the 7 mix designs per fibre at 14, 28, 56, 90 and 180 days). The specimens were centred between the two supports of the hydraulic press of a Hounsfield universal tester (Model H10KS) with a load capacity of $1000 \mathrm{KN}$ (Figure 7). The loading was then applied gradually at a steady rate of 2.0 $\mathrm{mm} / \mathrm{min}$ until failure.

All property values presented in this study are averaged from five specimens. Individual variations higher than $\pm 5 \%$ of the average values were not considered.
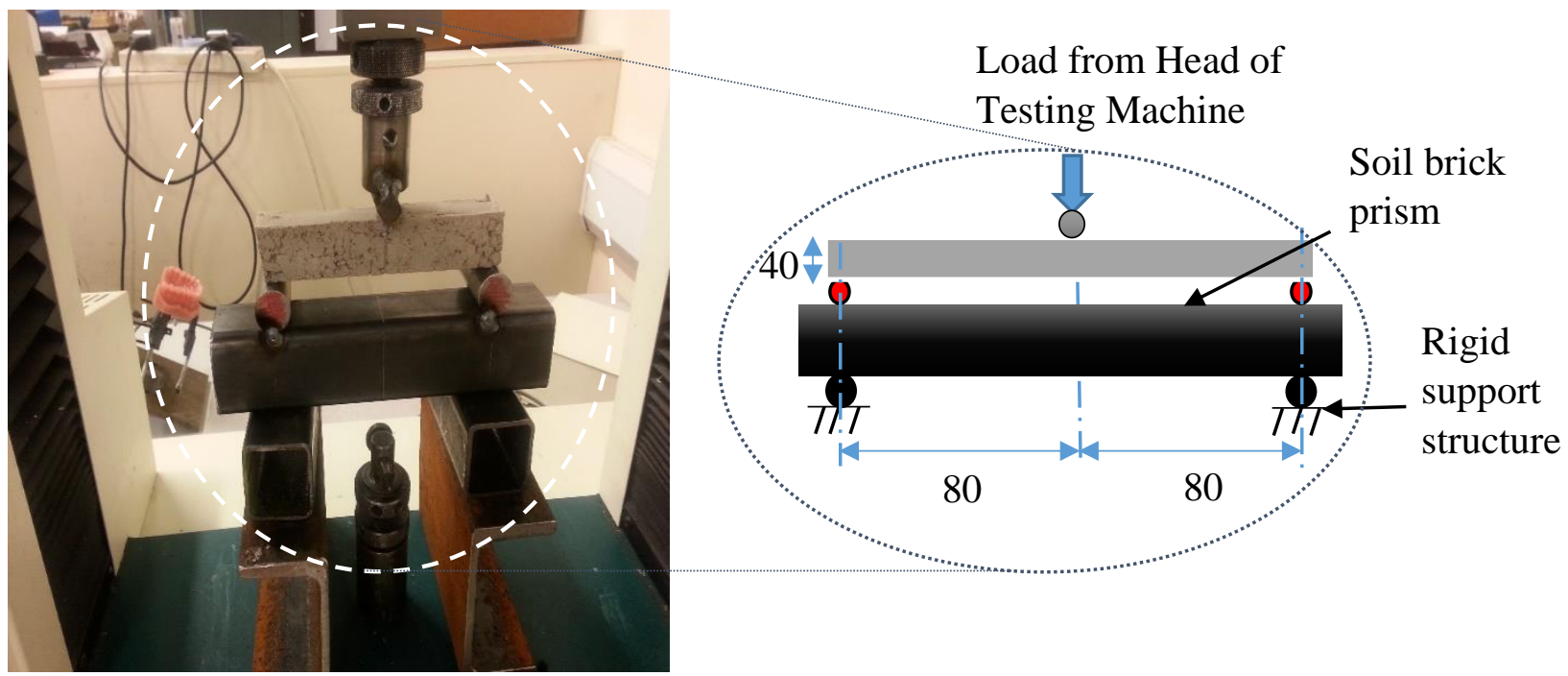

Figure 7: The experimental set-up for the three-point bending test.

\section{Results and discussion}

\subsection{Raw materials characterisation}

\subsubsection{Tensile strength of CFF and SBF}

Mean tensile strength values from five specimens, as well as their Standard Deviation (SD) and

Coefficient of Variation (CV) are presented in Table 4. The observed tensile behaviour of the individual fibres was found to be linear-elastic until failure (sudden - brittle failure). 


\begin{tabular}{cccccc}
\hline Fibre & $\begin{array}{c}\text { Strain at failure } \\
(\mathbf{m m} / \mathbf{m m})\end{array}$ & $\begin{array}{c}\text { Young's } \\
\text { modulus } \\
(\mathbf{M P a})\end{array}$ & $\begin{array}{c}\text { Tensile } \\
\text { strength } \\
(\mathbf{M P a})\end{array}$ & $\begin{array}{c}\text { Elongation } \\
\text { point at } \\
\text { break \% }\end{array}$ \\
\hline Mean & CFF & 0.009 & 38.42 & 16.89 & 8.20 \\
$\mathrm{SD}$ & $\mathrm{C}$ & 14.082 & 2.11 & 0.86 \\
$\mathrm{CV} \%$ & 10.98 & 14.65 & 12.49 & 10.49 \\
\hline Mean & & 0.075 & 212.41 & 15.47 & 7.47 \\
$\mathrm{SD}$ & $\mathrm{SBF}$ & 0.008 & 34.73 & 1.83 & 0.84 \\
$\mathrm{CV} \%$ & & 10.67 & 16.35 & 11.83 & 11.24 \\
\hline
\end{tabular}

\subsubsection{XRD analysis}

235 X-ray diffraction (XRD) was used to examine the mineralogical composition of the soil. The powder X-ray diffraction pattern of the soil sample is shown in Figure 8. The X-ray diffraction revealed that the sample was composed mainly of quartz which is rich in silica $\left(\mathrm{SiO}_{2}\right)$, kaolinite $\left(2 \mathrm{SiO}_{2} \mathrm{Al}_{2} \mathrm{O}_{3}-2 \mathrm{H}_{2} \mathrm{O}\right)$, illite $\left(\mathrm{K} \mathrm{Al} 2\left(\mathrm{Al} \mathrm{Si}_{3}\right) \mathrm{O}_{10}(\mathrm{OH})_{2}\right)$, goethite $\left(\mathrm{Fe}_{2} \mathrm{O}_{3} \mathrm{H}_{2} \mathrm{O}\right)$ and a small amount of calcite $\left(\mathrm{CaCO}_{3}\right)$. The XRD pattern shown for soil suggests the presence of quartz mineral $\left(\mathrm{SiO}_{2}\right)$ as the main soil minerals (54.1\%), also proven by chemical composition represented in

Table 5. Presence of quartz contributes to improved quality of soil bricks.

Table 5: Chemical composition of the soil sample.

\begin{tabular}{lllllllllll}
\hline Oxides & $\mathrm{SiO}_{2}$ & $\mathrm{Al}_{2} \mathrm{O}_{3}$ & $\mathrm{Fe}_{2} \mathrm{O}_{3}$ & $\mathrm{MgO}$ & $\mathrm{CaO}$ & $\mathrm{MnO}$ & $\mathrm{Na}_{2} \mathrm{O}$ & $\mathrm{K}_{2} \mathrm{O}$ & $\mathrm{TiO}_{2}$ & LOI \\
\hline Wt. \% & 54.1 & 15.5 & 5.8 & 1.2 & 6.4 & 0.04 & 0.03 & 1.4 & 0.3 & 15.2
\end{tabular}




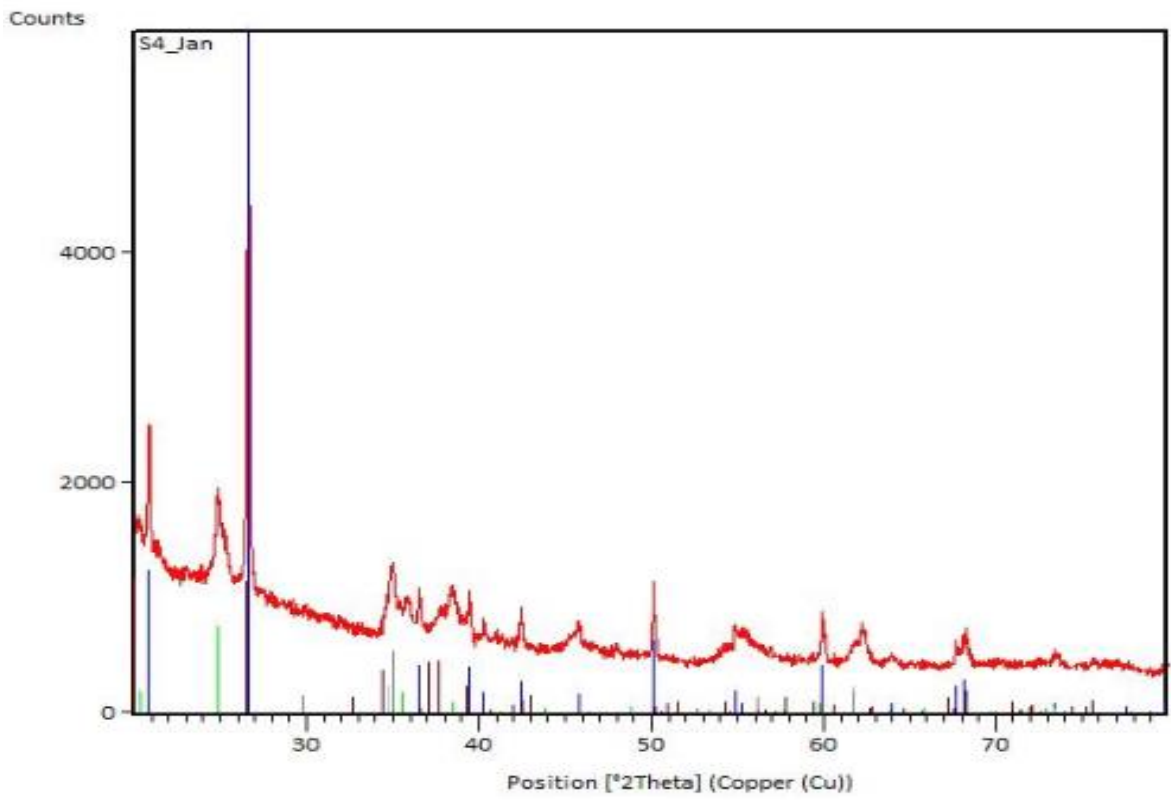

251

Figure 8: X-ray diffraction pattern of soil

252 The next most abundant component is kaolinite $\left(2 \mathrm{SiO}_{2} \mathrm{Al}_{2} \mathrm{O}_{3}-2 \mathrm{H}_{2} \mathrm{O}\right)$. At constant $\mathrm{pH}$, strength 253 increases with kaolinite content [33]. Another important component observed is goethite $254\left(\mathrm{Fe}_{2} \mathrm{O}_{3} \mathrm{H}_{2} \mathrm{O}\right)$, which may often be the cause of efflorescence in soil bricks. As a result, it is 255 considered best practice to keep the ferric oxide content at less than $10 \%$ by weight [34].

256 X-ray diffraction (XRD) for CFF and SBF were also carried out and results presented in Figures 2579 and 10 respectively. It is well known that feather keratin is semi-crystalline and naturally 258 macromolecular, its XRD profiles have confirmed this hypothesis. This semi-crystallinity also 259 plays an important role in higher strength and stiffness of feathers. 


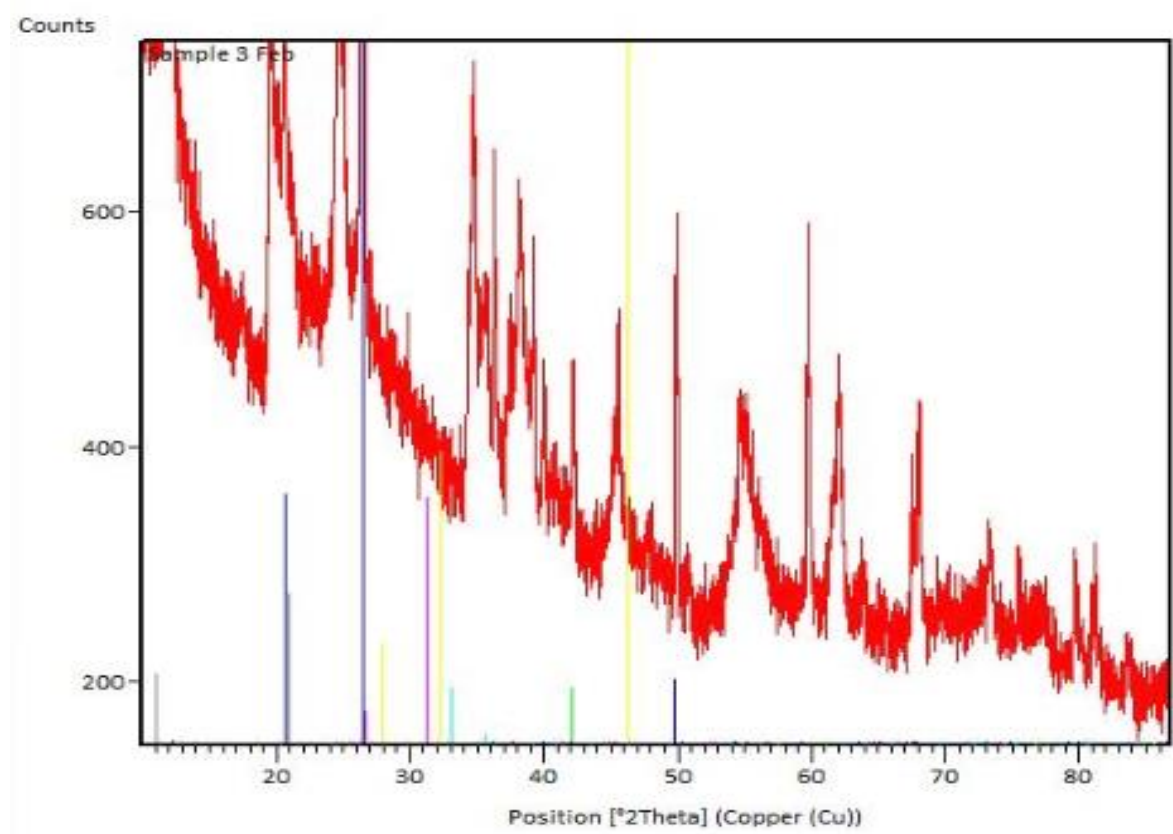

269

Figure 9: X-ray diffraction pattern of chicken feather fibres (CFF).

The XRD analysis carried out on powder SBF presents some peaks of calcite $\left(\mathrm{CaCO}_{3}\right)$,

271 presence of quartz $\left(\mathrm{SiO}_{2}\right)$ and traces of microcline $\left(\mathrm{KAlSi}_{3} \mathrm{O}_{8}\right)$. The calcite phase is explained

272 by the carbonation effect, which is caused by the reaction between $\mathrm{Ca}(\mathrm{OH})_{2}$ and $\mathrm{CO}_{2}$ present

273 in the atmosphere. The amount of calcite in the soil brick specimens increased with increase in

274 the percentage of SBF.

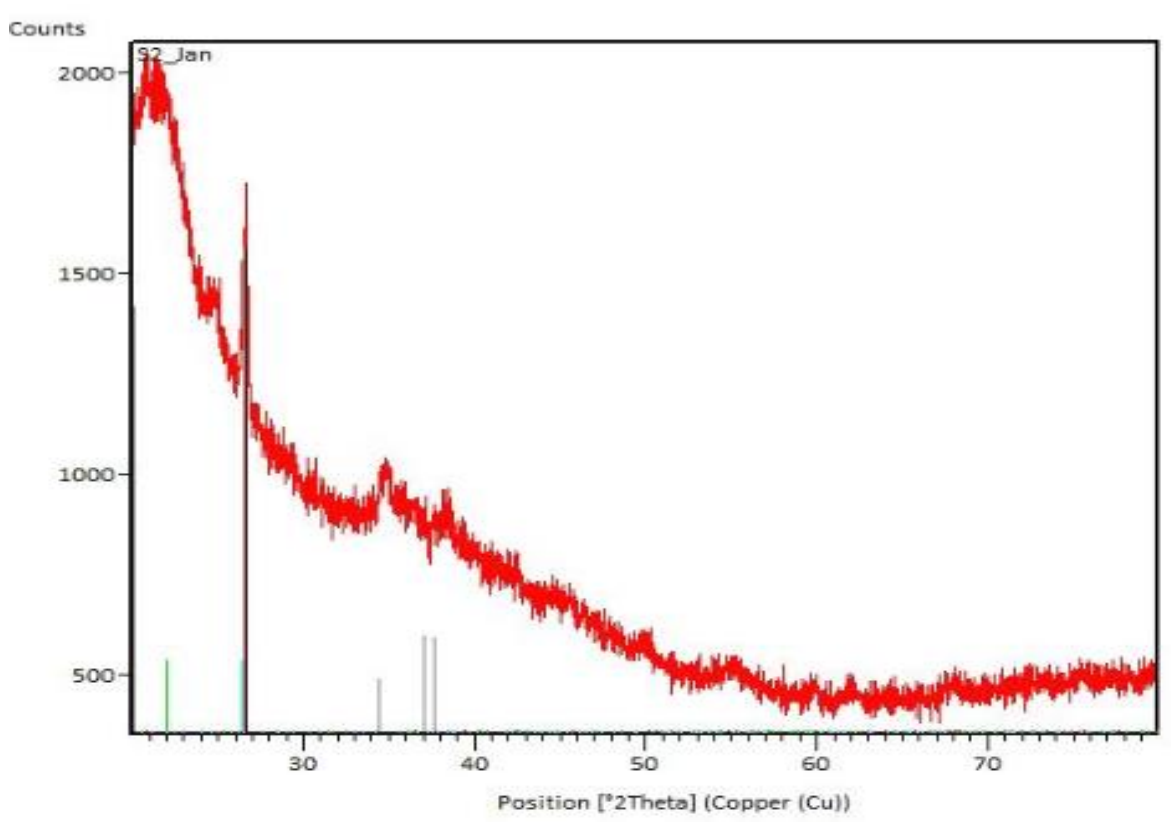

Figure 10: X-ray diffraction pattern of sugarcane bagasse fibres (SBF). 


\subsubsection{SEM examination and EDX analyses} compared to CFF.

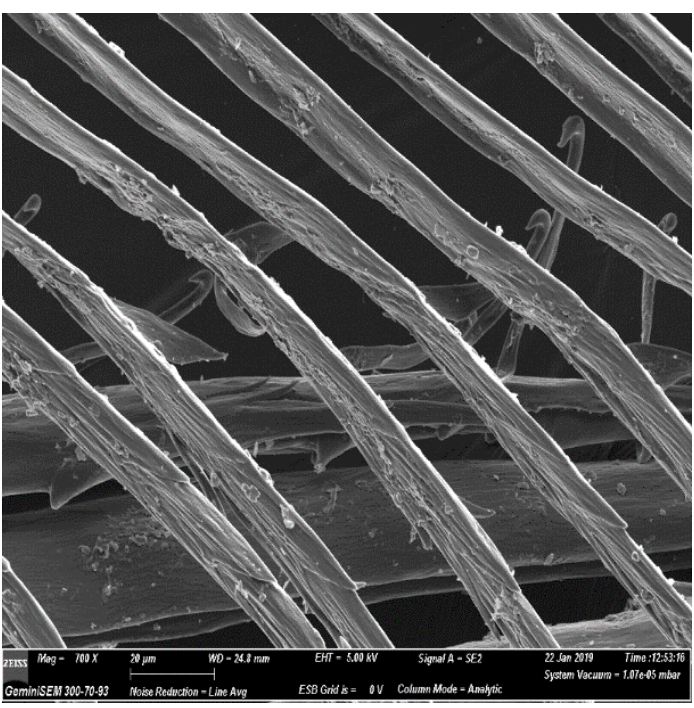

(a)

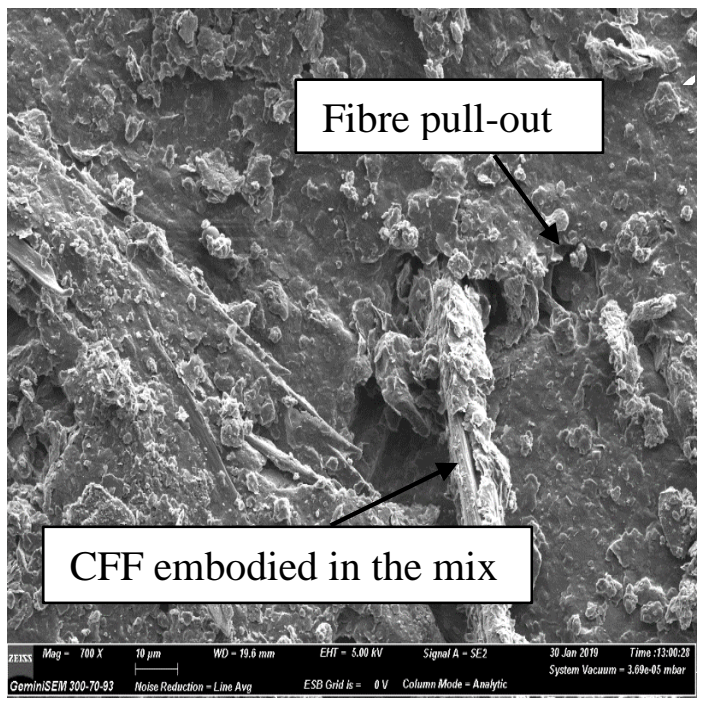

(b)

Figure 11: Backscattered SEM images of raw materials (a) CFF, and (b) CFF within soil bricks. 


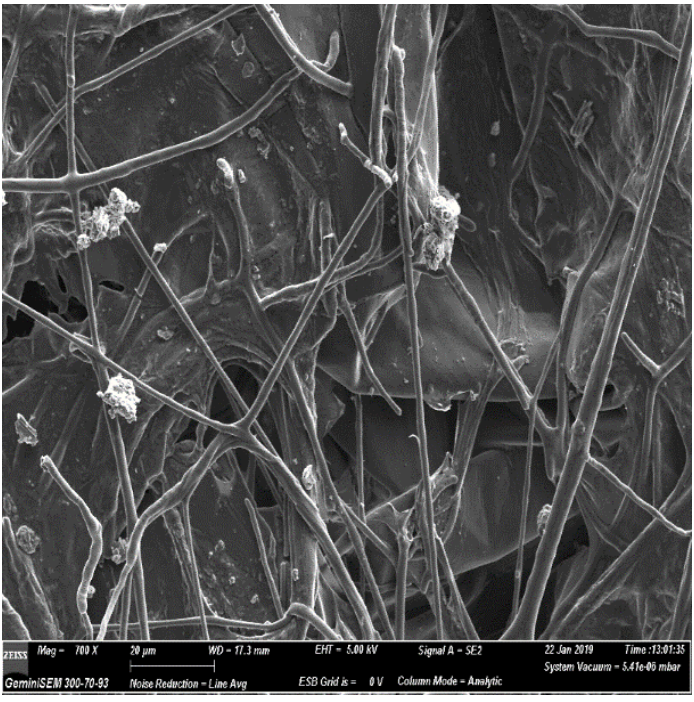

(a)

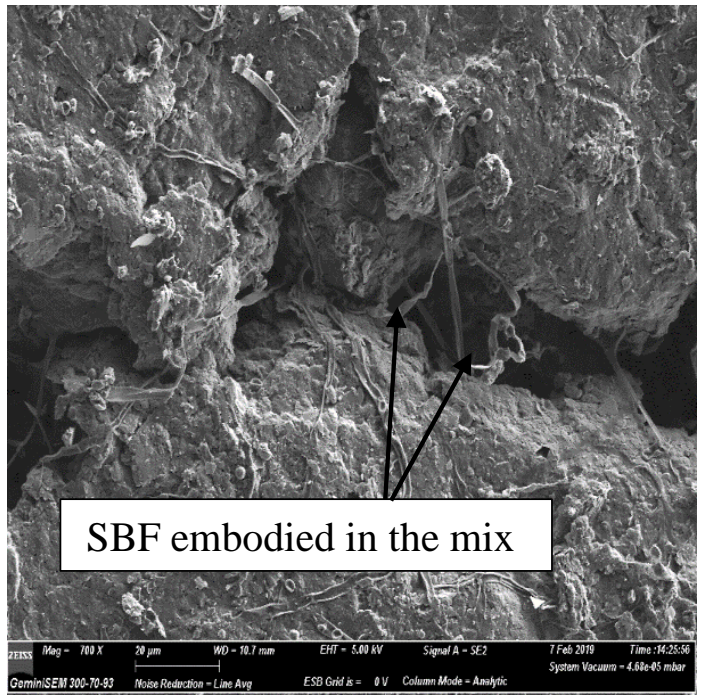

(b)

Figure 12: Backscattered SEM images of raw materials (a) SBF, and (b) SBF within soil bricks.

It is evident that CFF have a hollow structure, with little protrusions along its length, while SBF show varied, irregular pores in texture which means that CFF have a more porous structure, which is responsible for the low-density value of the CFF. The feathers have long shafts and barbs and a smooth surface, which is evident in the magnified image of the fibre.

Fibres pull-out and the fracture was observed as shown in Figures $11 \mathrm{~b}$ and $12 \mathrm{~b}$. This observation was an indication that the fibres used had a high pull-out resistance. During the transfer of stresses from the matrix to fibres, the de-bonding that takes place at the fibres matrix interface when fibres are pulled-out from matrices and generates frictional energy losses, which in turn contribute to composite toughness.

Figure 13a shows an SEM image of the fibre distribution inside the soil bricks. The figure represents the typical SEM images taken at the top surface of the sample, uniform distribution of fibres in the brick samples can be seen. The fibres were separated from each other during the extrusion process and they are well-dispersed in the soil matrix. It can also be noticed that the fibre particle directions are in different directions within the sample. The images show a 
good fibre distribution in the soil matrix and reveal that fibres have good adhesion to the soil matrix. There are some regions of intermediate modification where the fibres have become damaged. A network is formed by fibres inside the composite as reinforcement during loading condition as shown in Figure 13b. The bridging mechanism of fibres in the composite is responsible for increase in strength with the increase in fibre content. The bridging effect can prevent crack propagation and enable effective stress transfer between the matrix and the fibres, leading to the enhanced compressive and tensile strengths.

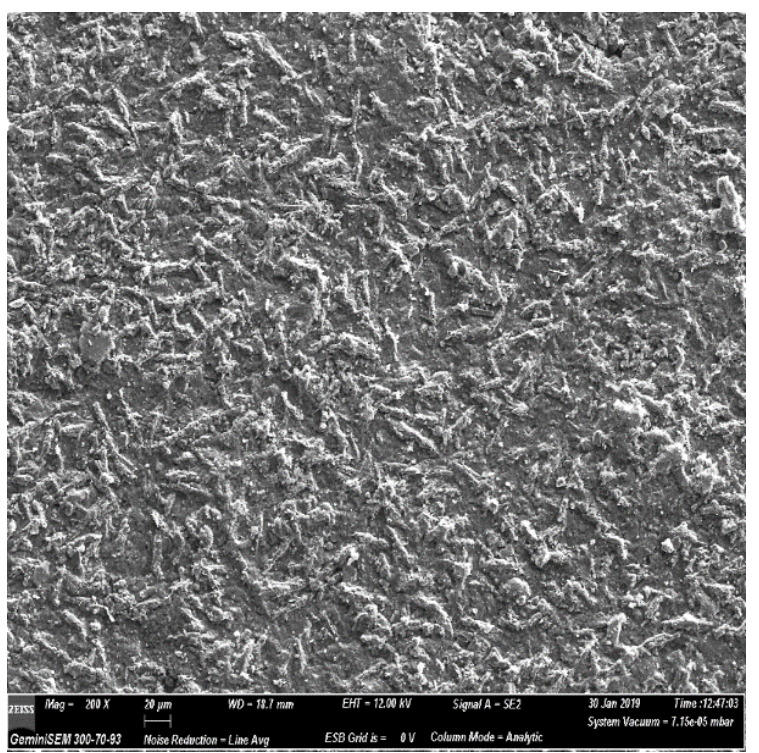

(a)

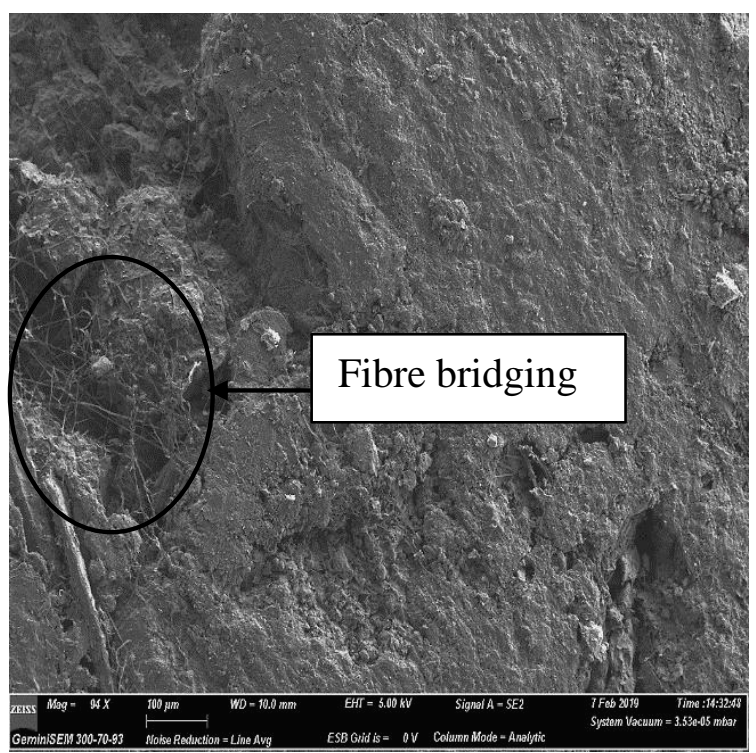

(b)

Figure 13: (a) SEM image of fibre distribution, and (b) fibre bridging in a failed sample.

344 The details of compound contents in CFF and SBF, as determined by EDX spectra from the

345 SEM are presented in Table 6. The most prominent elements observed are carbon (C) and silicon $(\mathrm{Si})$, indicating their suitability for use in soil brick mix. Traces of other minor phases such as calcium $(\mathrm{Ca})$, aluminium $(\mathrm{AL})$, oxygen $(\mathrm{O})$ and sulphur $(\mathrm{S})$ were also detected. In general, the SEM scans and EDX analysis appear to corroborate the findings of the XRD analysis. The high amount of silicon ( $\mathrm{Si}$ ) in SBF indicate that this fibre comes from a silicatetype as confirmed by XRD tests. 
Table 6: The quantification of compound contents in CFF and SBF.

\begin{tabular}{ccc} 
Symbol & cps/eV $(\mathrm{CFF})^{*}$ & cps/eV (SBF)* \\
\hline $\mathrm{Si}$ & 5 & 280 \\
$\mathrm{Ca}$ & 10 & 15 \\
$\mathrm{~S}$ & 20 & 5 \\
$\mathrm{O}$ & 30 & 40 \\
$\mathrm{C}$ & 320 & 220 \\
$\mathrm{Al}$ & 20 & 30 \\
\hline
\end{tabular}

352

* cps/eV: counts per second per electron-vol.

\subsection{Soil specimens}

\subsubsection{Physical properties}

\subsubsection{Bulk density}

The density of soil bricks has a significant impact on its mechanical properties. Figures 14 and 15 present the bulk density for CFF reinforced soil bricks and SBF reinforced soil bricks at 14, 28, 56, 90 and 180 days respectively. Control sample has the highest density of $1.68 \mathrm{~g} / \mathrm{cm}^{3}$. With $11 \%$ CFF or SBF at 14 days, density decreases to 1.33 and $1.39 \mathrm{~g} / \mathrm{cm}^{3}$ respectively. This expected and due to the low fibre density on one hand and an increase in porous structure caused by fibre addition on the other hand.

Generally, bulk density decreases with increase in the age of the soil bricks. The samples reinforced with CFF and SBF showed a density of 1.28 and $1.30 \mathrm{gm} / \mathrm{cm}^{3}$ at the end of the $180-$ day curing period. Generally, bulk density of samples with SBF is higher than samples with CFF. This due to CFF containing less solid material than SBF as presented in Table 2.

At 56 days, reduction in bulk density of $8.7 \%\left(1.37 \mathrm{gm} / \mathrm{cm}^{3}\right)$ and $5.3 \%\left(1.42 \mathrm{gm} / \mathrm{cm}^{3}\right)$ were recorded for $7 \% \mathrm{CFF}$ and $5 \% \mathrm{SBF}$ respectively, compared to the control sample at 56 days. This is higher than the reduction of $1.64 \%\left(1.79 \mathrm{gm} / \mathrm{cm}^{3}\right)$ for wool reinforced soil bricks 

structure as well as easing bricks handling.

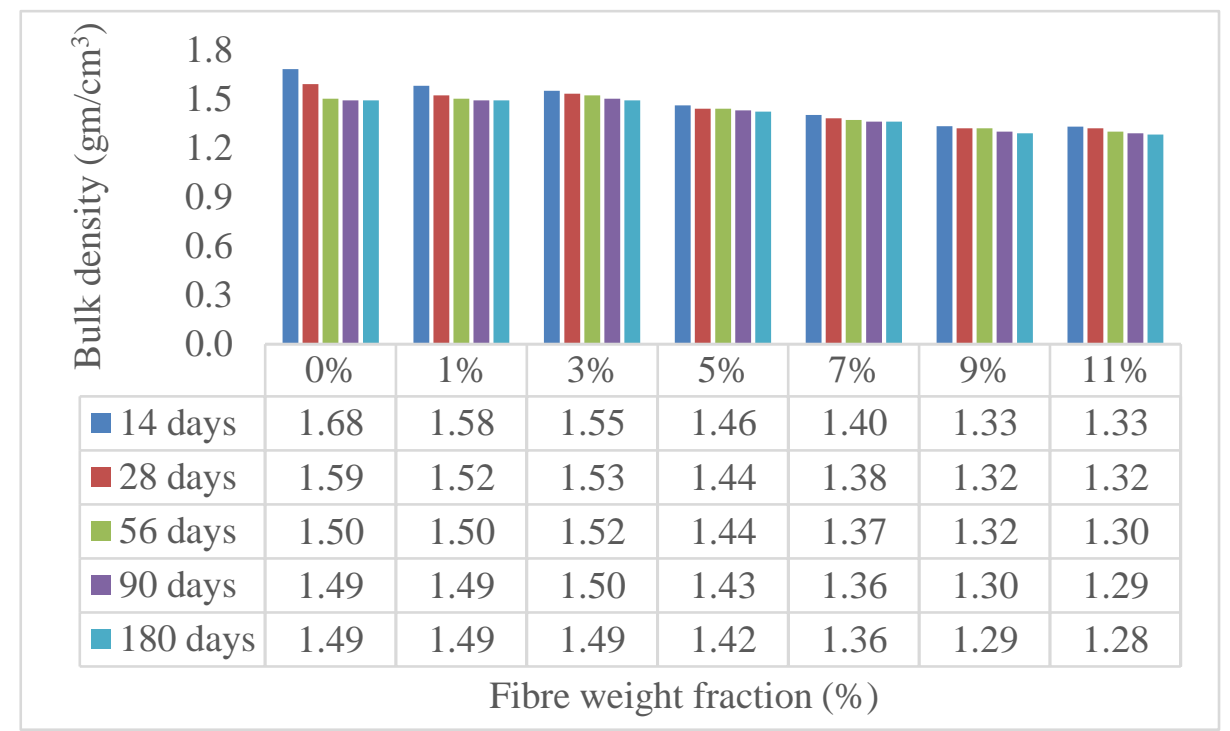

Figure 14: Change in density of CFF reinforced soil bricks with time.

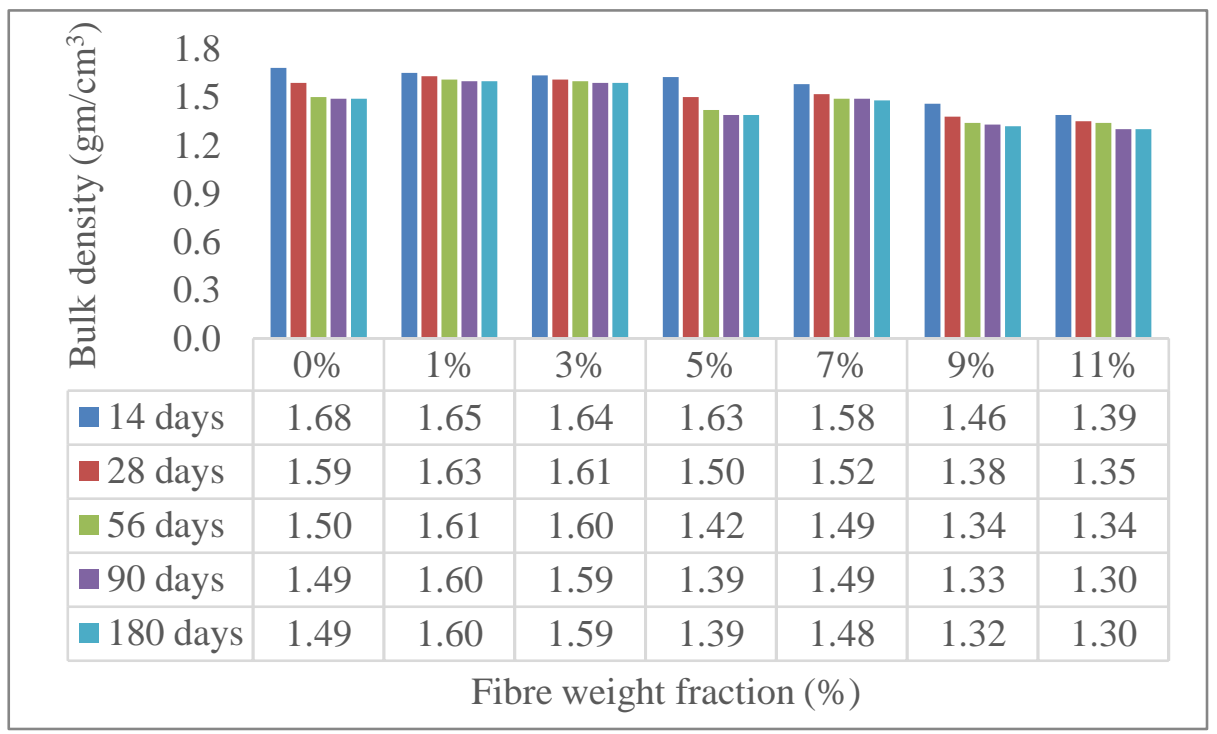

Figure 15: Change in density of SBF reinforced soil bricks with time.

\subsubsection{Durability properties}

\subsubsection{Water absorption}

Water absorption is an indicator of the resistance of soil bricks to immersion. Figures 16 and

17 illustrate the variation of water abortion of CFF-soil bricks and SBF-soil bricks at 14, 28, 
content. At $11 \%$ fibre addition at 14 days, there is a $45.8 \%(17.5 \%)$ and $36.7 \%(16.4)$ increase

393

394

395

396

397

398

399

400

401

402

403

404

405

406

407

408

409

410

411

412

413 in the water absorption of samples reinforced with CFF and SBF respectively, compared to the control sample, which has lowest water absorption values of $12 \%$. This is attributed to the water absorption capacity of the fibres as well as the increased porous nature and the void spaces within the reinforced samples due to the inclusion of natural fibre [35].

Water abortion decreases with increase in the age of the soil bricks up to 56-day then remains almost constant. It was observed that the percentage of water absorption for different mix types varied from $12.0 \%$ to $17.5 \%$ for samples with CFF, $12.0 \%$ to $16.4 \%$ for samples with SBF and $11.0 \%$ to $12.0 \%$ for control samples. As expected, lower densities due to light fibres lead to higher water absorption. This result is in agreement with that of Zak et al. [36] for the sisal stabilised soil blocks.

Based on the test results, the maximum water absorption values for all the reinforced mixtures $(17.5 \%)$ is within the acceptable limit for soil bricks of $\leq 18.0 \%$ as per ASTM C20-00 [37]. The recorded water absorption in this study is adequate for residential earth building. However, high rate of water absorption may cause swelling which leads to loss of strength with time in unprotected environment such as rainfall [38].

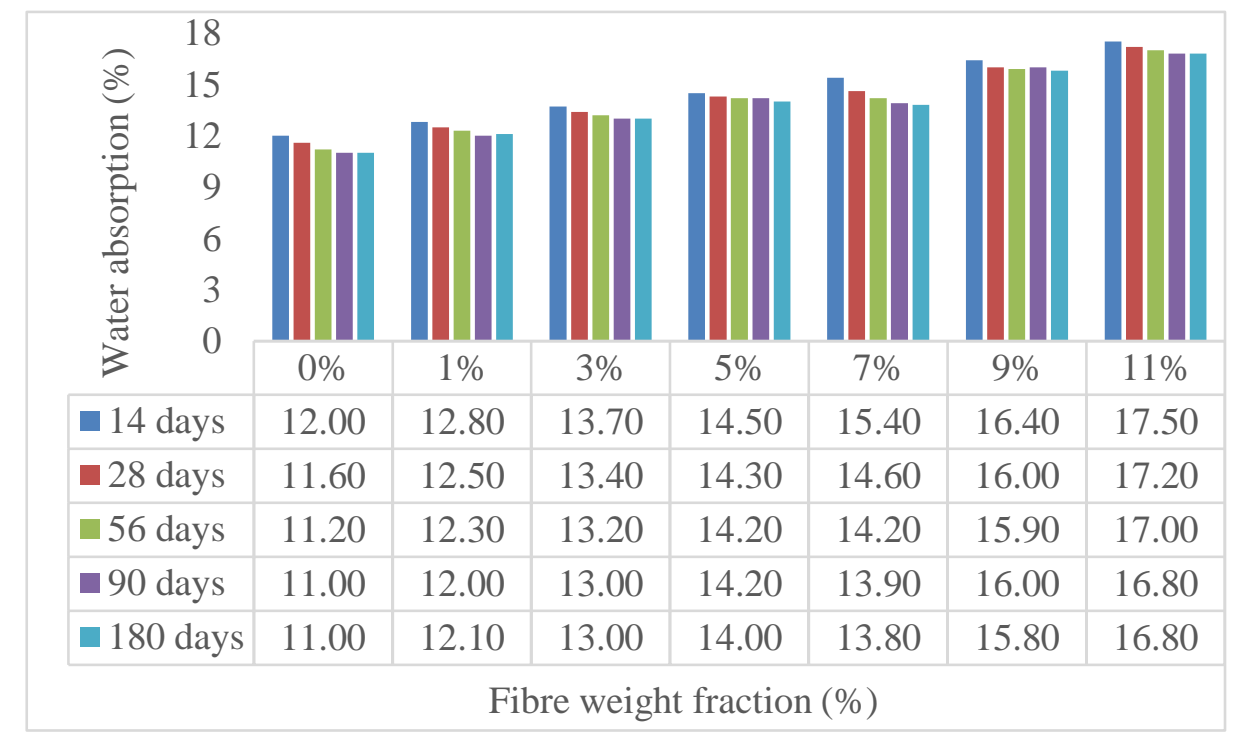

Figure 16: Change in water absorption CFF reinforced soil bricks with time. 
Different fibre lengths of CFF and SBF in the soil mix were used to establish the optimum length for maximum strength.

Figures 18 and 19 show the compression test results with four different fibre lengths; 5, 10, 15 and $20 \mathrm{~mm}$ of fibre reinforced soil bricks at 14 days. The behaviour of CFF and SBF is similar, with strength improvement recorded in both cases. Increase in length of the fibres results in an enhancement in soil compressive and tensile strength properties. This is due to the increase in the contact area with the soil, which results in an improvement in the strength and stiffness of the composite. This behaviour is observed up to a certain limit of fibre length and beyond which strength reduces partly due to the reduction of soil-soil bonds with increased fibre volume. In addition, individual fibres are overlapped and twisted around each other and the formation of soil-fibre is also reduced with consequent overall reduction in the strength of the composite. embedded length is sufficient to develop full strength capacity. Therefore, the length of fibres plays a significant role in the compressive strength improvement of soil bricks. 


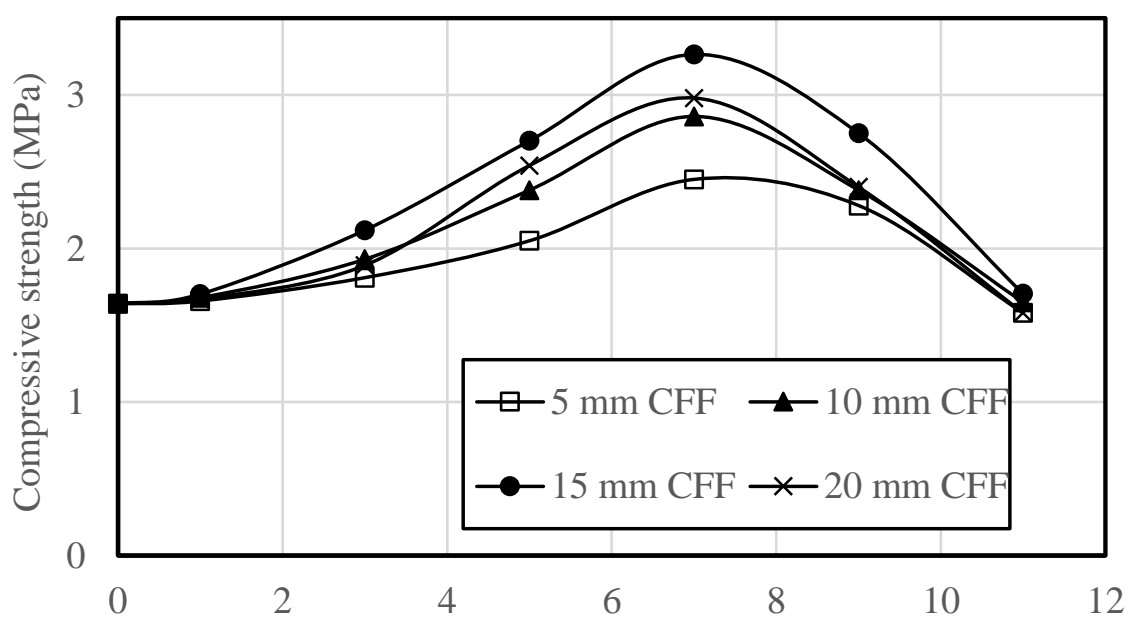

Fibre weight fraction (\%)

Figure 18: Compressive strength variation with CFF length at 14 days.

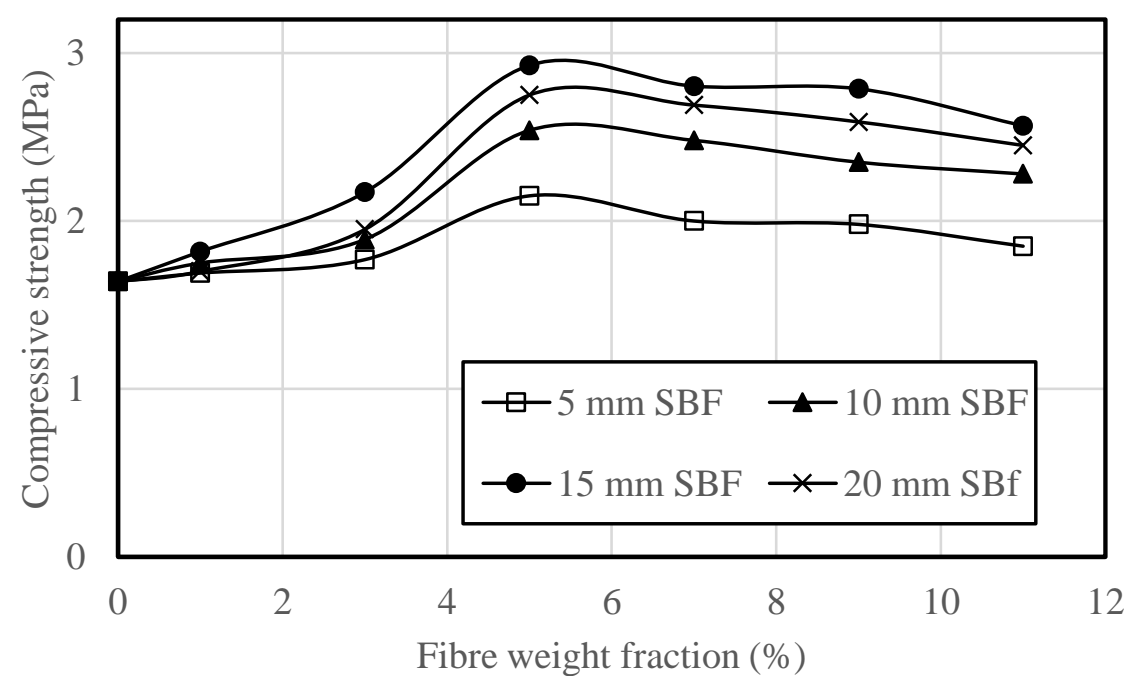

Figure 19: Compressive strength variation with SBF length at 14 days.

The fibre length determines the pull-out resistance of the embedded fibres in the soil matrix and therefore directly determines the reinforcement force, which is less than or equal to the fibre tensile strength. The amount of fibres determines the intensity of the reinforcement: for small amounts (up to $7 \% \mathrm{CFF}$ or $5 \% \mathrm{SBF}$ by weight), the strength of the reinforcement increases with the number of fibres. However, at a higher fibre weight fraction over a certain threshold, the fibres are so numerous that they weaken the soil matrix as fibre-fibre bond significantly increased and thus lead to lower resistance of the reinforced soil composites. 
Figures 20 and 21 show the influence of fibre length on tensile strength of fibre reinforced soil bricks at 14 days. Tensile strength increases with increase in fibre length up to a certain limit. The length of the fibre plays a major role in enhancing the tensile strength because its increase will directly increase the bond length. This is due to the fact that area in contact with soil is comparatively large and therefore there is a subsequent improvement in strength and stiffness of bricks. The lengths of the fibres used in this study were a result of the optimum lengths of 15-mm of CFF and SBF.

469

470

471

472

473

474

Figure 20: Tensile strength variation with CFF length at 14 days.

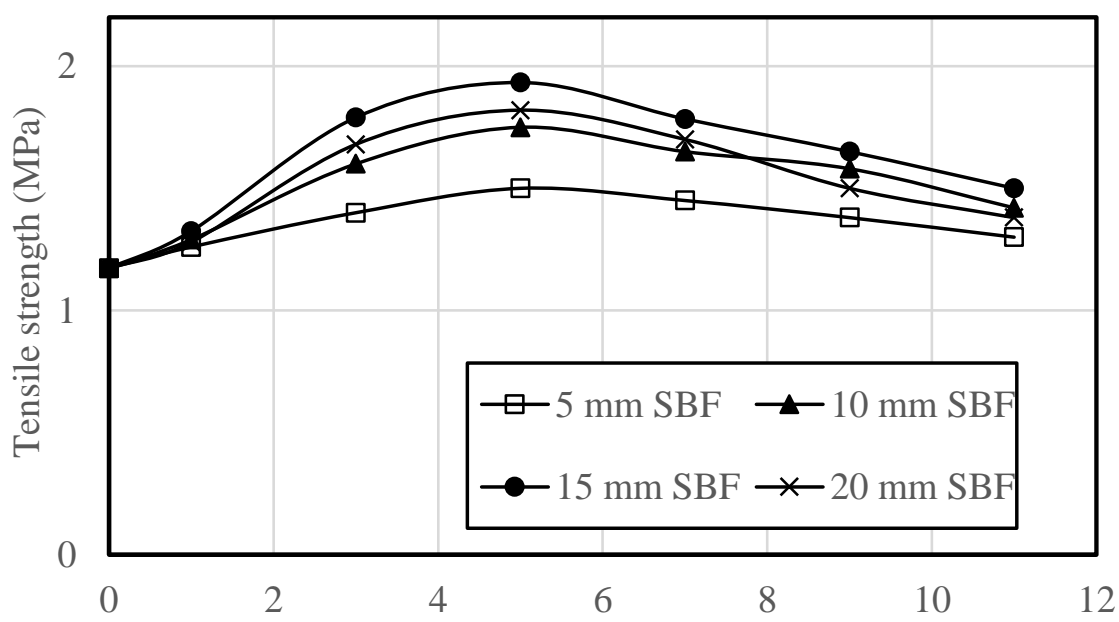

Fibre weight fraction (\%)

Figure 21: Tensile strength variation with SBF length at 14 days. 
485

486

487

488

489

490

491

492

493

494

495

496

497

498

499

500

501

502

503

504

505

506

507

Figures 22 and 23 show the variation of compressive strength of CFF reinforced soil bricks and SBF reinforced soil bricks at 14, 28, 56, 90 and 180 days respectively. Results showed that adding CFF and SBF increases compressive strength by $98.8 \%$ (3.26 MPa) and 78.7\% (2.93 $\mathrm{MPa}$ ) respectively compared to unreinforced sample (control sample) at 14 days. This means that with increased compressive strength, wall width can be reduced for practical purposes, thereby, resulting in increased internal room size. This would address the issue of narrow room sizes which earlier existed in old houses.

Improvement in compressive strength of $1.7 \%, 2.8 \%, 10.7 \%, 31.0 \%$ and $14.8 \%$ were recorded for $1 \%, 3 \%, 5 \% 7 \%$ and $9 \%$ CFF addition at 56 days. For SBF reinforced soil bricks, increase of $1.7 \%, 3.8 \%, 25.8 \%, 16.2 \%$ and $9.7 \%$ were recorded at 56 days for $1 \%, 3 \%, 5 \% 7 \%$ and $9 \%$ SBF addition. At 180 days, increase in compressive strength of $6.7 \%(4.14 \mathrm{MPa})$ and $0.5 \%$ (3.90 $\mathrm{MPa}$ ) were documented for $7 \% \mathrm{CFF}$ and 5\% SBF inclusion respectively, compare to control mix (3.88 MPa).

The optimal reinforcement ratio in this study is $7 \%$ for CFF and 5\% for SBF. Generally, the compression strength values obtained in this study range between 1.64 - 3.88 MPa for control samples, 1.70 - 4.29 MPa for CFF-soil bricks and 1.82 - 3.98 MPa for SBF-soil bricks. This is similar to the values of polystyrene soil bricks (1.90 - 4.20 MPa) [13] and better than the values of $0.80-1.10 \mathrm{MPa}$ for coconut soil bricks and 0.95 - 1.15 MPa for oil palm soil bricks [39].

At 90 days, reduction in compressive strength of $11.9 \%(3.12 \mathrm{MPa})$ and $14.1 \%(3.04 \mathrm{MPa})$ were reported for $9 \%$ inclusion of either CFF and SBF when compared to the control mix (3.54 $\mathrm{MPa})$. At $11 \%$ fibre addition, greater reduction in compressive strength $42.4 \%$ (2.04 MPa) and $20.3 \%$ (2.82 $\mathrm{MPa}$ ) for $\mathrm{CFF}$ and $\mathrm{SBF}$ respectively compared to control mix (3.54 MPa) were recorded. In addition, at 180 days, deterioration in compressive strength of 3.6\%, 5.4\%, 4.1\%, 
522

523

524

525

526

527

528

$3.5 \%, 6.7 \%$ and $1.0 \%$ were recorded for $1 \%, 3 \%, 5 \% 7 \%, 9 \%$ and $11 \%$ CFF addition, compare to their values at 90 days. For SBF reinforced soil bricks, reduction of 10.4\%, 7.8\%, 2.0\%, $1.9 \%, 3.9 \%$ and $1.4 \%$ were recorded at 180 days for $1 \%, 3 \%, 5 \% 7 \%, 9 \%$ and $11 \%$ SBF addition, compare to their values at 90 days.

Beyond 90 days, loss in compressive strength is due to degradation of CFF/SBF surface in contact with the soil matrix. An examination of the failed fibre reinforced samples shows that $\mathrm{CFF} / \mathrm{SBF}$ began to separate into fibrils due to reduction in bond strength between CFF/SBF and the surrounding soil matrix. Also, natural fibres are sensitive to humidity and show an enormous capacity for water absorption during curing which leads to strength reduction over time. This phenomenon of natural fibre degradation over the long term can be minimised through fibre surface alkali treatment (e.g. with Sodium Hydroxide solution) which is outside the scope of the present work and is recommended for future work on natural fibre reinforced soil bricks. It is envisaged that fibre treatments will improve the fibre/matrix adhesion by increasing the surface roughness of natural fibres [38].

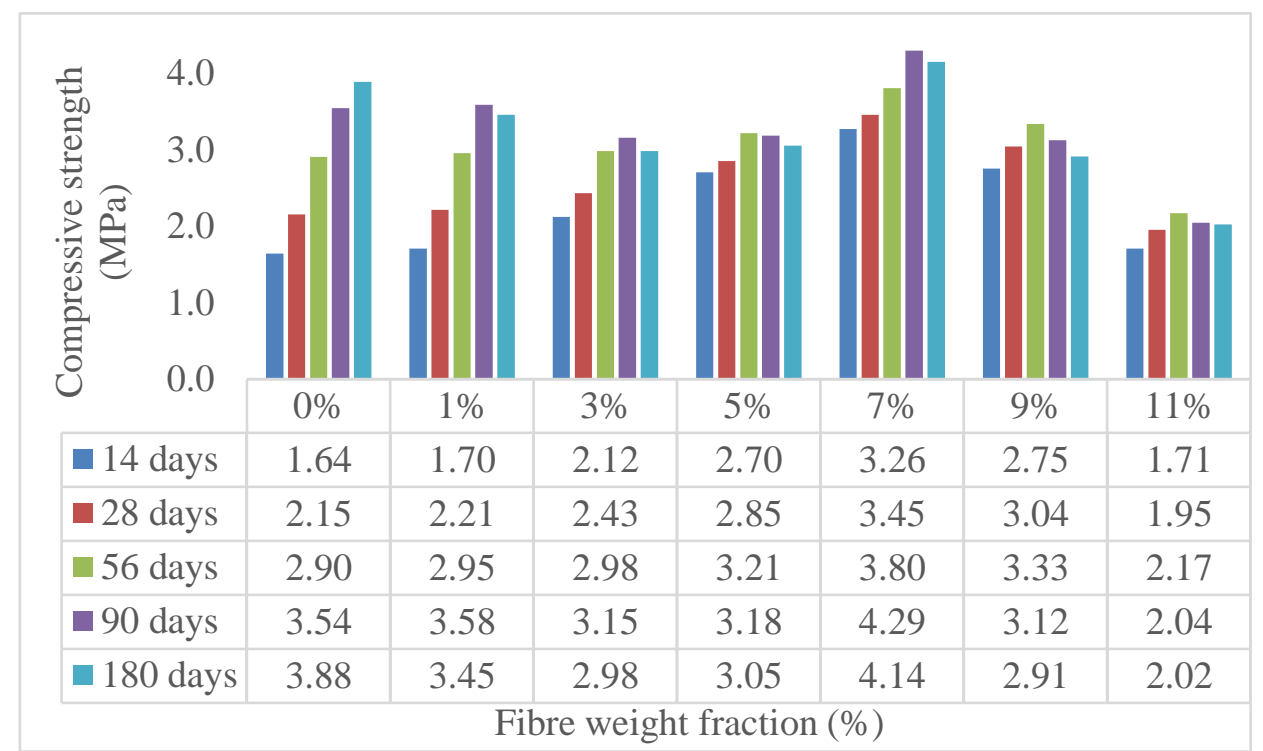

Figure 22: Compressive strength of CFF reinforced soil bricks at 14, 28, 56, 90 and 180 days. 
Figure 23: Compressive strength of SBF reinforced soil bricks at 14, 28, 56,90 and 180 days.

The recommended minimum compressive strength of soil bricks in international standards varies between 1.0 MPa in Turkish Standard [40] and 2.1 MPa in American local building codes [41]. Typical compressive strength of manually pressed soil bricks in literature is less than 5.0 $\mathrm{MPa}$ as documented in [8-10]. Compressive strength of CFF reinforced soil bricks and SBF reinforced soil bricks reported in this study satisfies all these requirements.

Strength of soil-fibre composite (reinforced samples) mainly depends on the formation of three bonds; fibre- soil, soil-soil, and fibre-fibre bonds. The strength of these bonds depends on the dimension, surface conditions, and quantity of fibres added to the soil. The fibre-soil bond is a new bond introduced in reinforced samples due to fibre addition and it is responsible for stress transmission within soil composite. This effect is known as fibres bridging mechanism in composite, as shown in Figure 13b. The fibre bridging mechanism binds soil grains together more firmly unlike in the case of unreinforced soil samples. This is responsible for increases in compressive and tensile strength with the increase in fibre content [42]. The soil--soil bond is the only bond existing in unreinforced samples and it is responsible for its strength. Finally, fibre-fibre bond is the weakest bond among the three bonds and do not contribute to the composite strength. Large quantities of fibres in composite mix, therefore, lead to increase in 
the formation of fibre-fibre bonds with corresponding decrease in soil-soil bonds. This will result in strength reduction. As a result, as fibre content increased above the optimum content ( $7 \%$ for $\mathrm{CFF}$ or $5 \%$ for SBF of $15 \mathrm{~mm}$ length fibres), increased fibre-fibre bonds was observed leading to a reduced compressive and tensile strength [30].

\subsubsection{Bending tensile strength}

A three-point bending test for prismatic specimens was carried out to calculate the bending tensile strength of the unreinforced and fibre reinforced soil bricks. Figures 24 and 25 summarizes the test results for CFF reinforced soil bricks and SBF reinforced soil bricks at 14, $28,56,90$ and 180 days. The bending tensile strength of soil bricks is improved by the addition of CFF or SBF. The increase in bending tensile strength is mainly due to the high tensile strength of these fibres. The force transmission between the soil particles is interrupted by the existence of fibres in the composite thus resisting more tensile stresses.

At $7 \%$ CFF addition, improvement in tensile strength of $97.4 \%, 66.4 \%, 49.1 \%, 50.9$ and $39.4 \%$ were recorded at 14, 28, 56, 90, 180 days. At 5\% SBF addition, increase in tensile strength of $65.0 \%, 40.6 \%, 30.4 \%, 30.2 \%$ and $19.4 \%$ were recorded at $14,28,56,90,180$ days. The mix containing 7\% CFF, or 5\% SBF represents an optimum point (peak values) for this study, as higher fibre inclusion resulted in a decrease of bending tensile strength. The reduction of the bending tensile strength can be attributed to the low fibre and soil bond as more fibre-fibre bonds was created with increase in fibre content.

The results of bending tensile strength of each mix type in this study exceeded the $0.395 \mathrm{MPa}$ recorded for corn soil bricks [43] and similar to 2.30 MPa for hemp soil bricks [44]. 


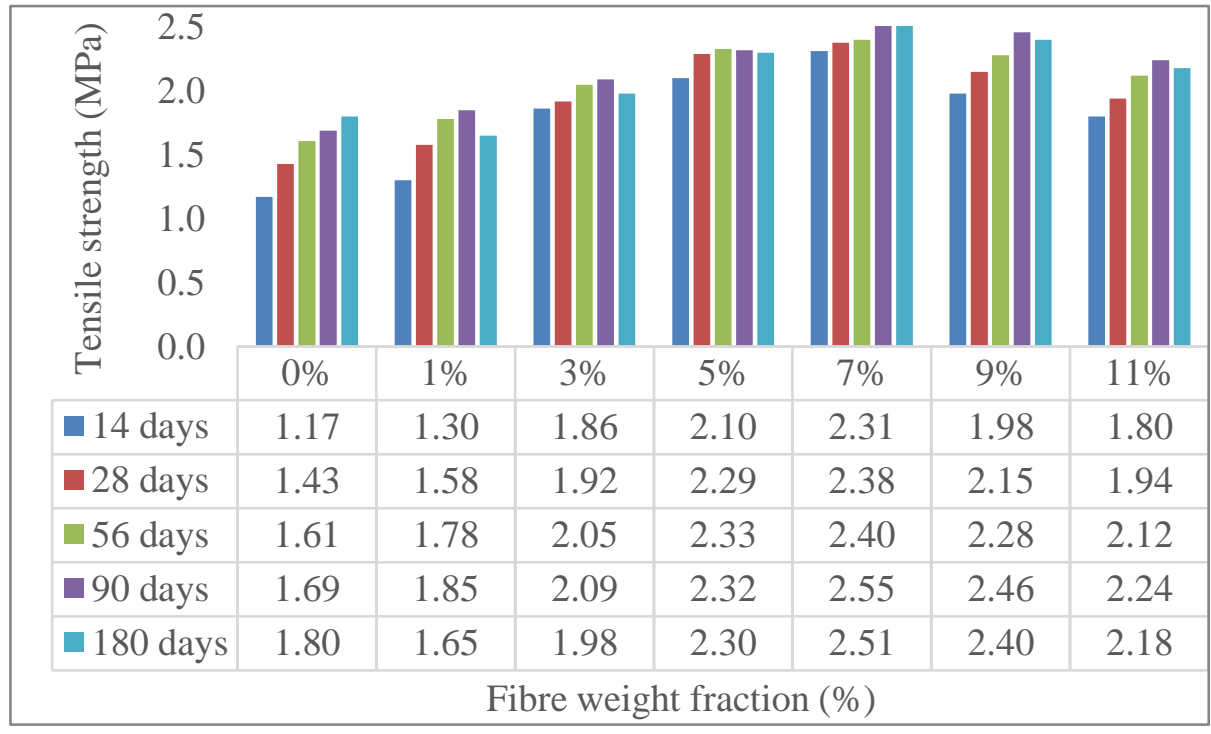

581

Figure 24: Bending tensile strength of CFF-soil bricks at 14, 28, 56, 90 and 180 days.

582

583

584

585

586

587

588

589

Figure 25: Bending tensile strength of SBF-soil bricks at 14, 28, 56, 90 and 180 days.

590

Figure 26 shows the typical failure pattern of the unreinforced and fibre reinforced soil bricks.

591 The failure of unreinforced samples was sudden (without warning) and occurs immediately

592 once the maximum load was reached in contrast to the more gradual failure ductile experienced

593 with the natural fibre reinforced samples. This improvement in ductility of fibre reinforced

594 specimens is due to fibre bridging mechanism observed in Figure 13b, which hold cracked parts together to delay failure after the maximum load is reached. 
596 Furthermore, the fibre reinforced samples stay as one piece without falling apart unlike the 597 unreinforced (control) samples. It does follow that the addition of CFF or SBF affect the brittle 598 behaviour of soil bricks. This is similar to failure pattern of waste-plastic fibre soil bricks [45] 599 and sisal fibres soil bricks [46].

600

601

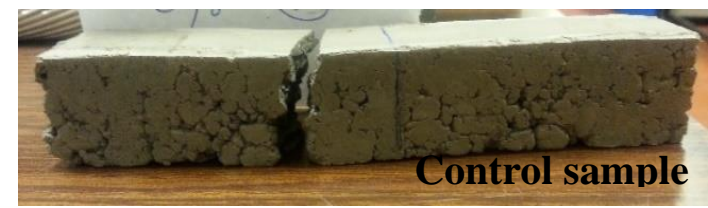

602

603

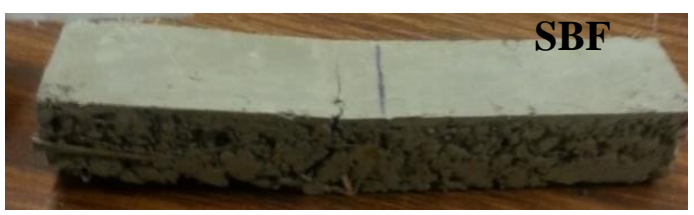

604

605

606
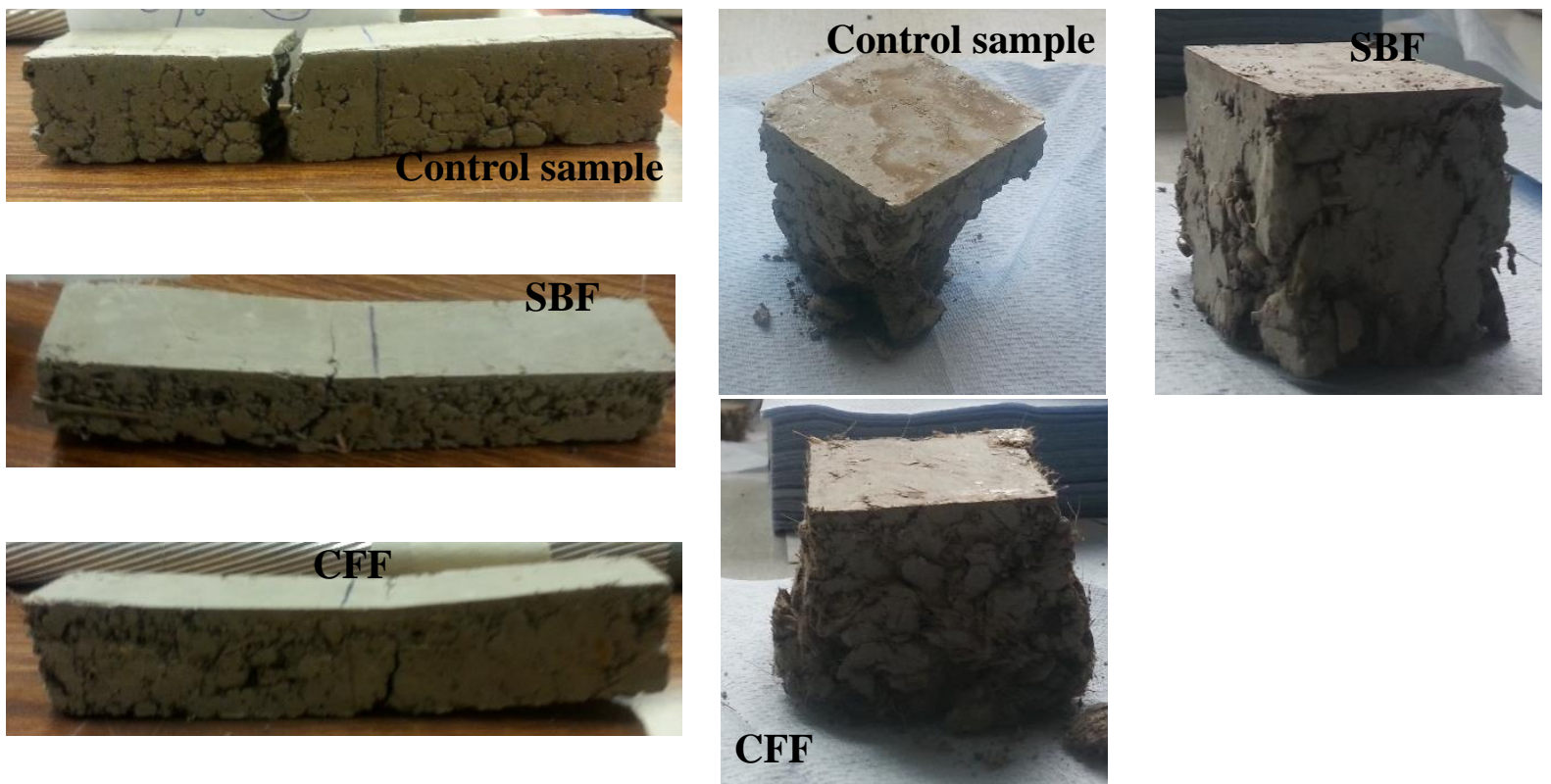

607

Figure 26: Typical failure modes of the unreinforced and fibre reinforced soil bricks.

\section{Constitutive models for natural fibre reinforced soil bricks}

609

\subsection{Constitutive relationship}

610 Based on the results of experimental work, the relationship between the key properties

611 investigated by this study was developed for both CFF and SBF soil bricks. These are bulk

612 density $B D$, compressive strength $\mathrm{f}_{\mathfrak{c}}$, tensile strength $\mathrm{f}_{\mathrm{t}}$ and fibre weight fraction $\mathrm{W}_{\mathrm{f}}$. Figure $27 \mathrm{a}$

613 shows the correlation between bulk density and CFF fibre weight fraction at 14 days as follows:

$614 \quad \mathrm{BD}_{\mathrm{CFF}}=-0.032 \mathrm{~W}_{\mathrm{f}}+1.638$

615 From which

616

$\mathrm{W}_{\mathrm{f}}=-31.25 \mathrm{BD}_{\mathrm{CFF}}+51.188$ 
617 Also, a cubic polynomial relation is observed between compressive strength, tensile strength 618 and fibre weight fraction at 14 days as shown in Figure 28a;

$619 \mathrm{f}_{\mathrm{c}, \mathrm{CFF}} / \mathrm{f}_{\mathrm{f}}=-0.004 \mathrm{~W}_{\mathrm{f}}^{3}+0.061 \mathrm{~W}_{\mathrm{f}}^{2}-0.236 \mathrm{~W}_{\mathrm{f}}+1.430$

620 Substituting $\mathrm{W}_{\mathrm{f}}$ with equation (1b) into equation (1c) and rearranging the equation;

$621 \mathrm{f}_{\mathrm{c}, \mathrm{CFF}}=65.892 \mathrm{f}_{\mathrm{t}} B \mathrm{D}^{3}-297.11 \mathrm{f}_{\mathrm{t}} B \mathrm{~B}^{2}+445.21 \mathrm{f}_{\mathrm{t}} \mathrm{BD}-220.41 \mathrm{f}_{\mathrm{t}}$

622 Using this relationship, the compressive strength of CFF reinforced soil brick at 14 days can

623 be predicted for a particular bulk density and tensile strength. Similar correlation for SBF 624 reinforced soil brick at 14 days can also be obtained;

$625 \quad \mathrm{BD}_{\mathrm{SBF}}=-0.025 \mathrm{~W}_{\mathrm{f}}+1.703$

626 Such that,

627

$f_{c, S B F}=43.217 f_{t} B D^{3}-202.48 f_{t} B D^{2}+314.04 f_{t} B D-159.66 f_{t}$

628 At 28 days,

$629 \quad \mathrm{BD}_{\mathrm{CFF}}=-0.026 \mathrm{~W}_{\mathrm{f}}+1.574$

630

$\mathrm{BD}_{\mathrm{SBF}}=-0.025 \mathrm{~W}_{\mathrm{f}}+1.641$

631 Such that,

$632 \mathrm{f}_{\mathrm{c}, \text { CFF }}=118.67 \mathrm{f}_{\mathrm{t}} \mathrm{BD}^{3}-515.86 \mathrm{f}_{\mathrm{t}} \mathrm{BD}^{2}+746.42 \mathrm{f}_{\mathrm{t}} \mathrm{BD}-358.15 \mathrm{f}_{\mathrm{t}}$

$633 \mathrm{f}_{\mathrm{c}, \mathrm{SBF}}=146.03 \mathrm{f}_{\mathrm{t}} \mathrm{BD}^{3}-661.34 \mathrm{f}_{\mathrm{t}} \mathrm{BD}^{2}+994.63 \mathrm{f}_{\mathrm{t}} \mathrm{BD}-495.09 \mathrm{f}_{\mathrm{t}}$

634 At 56 days,

$635 \quad \mathrm{BD}_{\mathrm{CFF}}=-0.021 \mathrm{~W}_{\mathrm{f}}+1.531$

636

$\mathrm{BD}_{\mathrm{SBF}}=-0.022 \mathrm{~W}_{\mathrm{f}}+1.585$

637 Such that, 
$639 f_{c, S B F}=-10.466 f_{t} B D^{3}+46.287 f_{t} B D^{2}-67.739 f_{t} B D+34.547 f_{t}$

640 At 90 days,

$641 \quad \mathrm{BD}_{\mathrm{CFF}}=-0.021 \mathrm{~W}_{\mathrm{f}}+1.519$

$642 \quad \mathrm{BD}_{\mathrm{SBF}}=-0.024 \mathrm{~W}_{\mathrm{f}}+1.577$

643 Such that,

$644 \mathrm{f}_{\mathrm{c}, \text { CFF }}=559.27 \mathrm{f}_{\mathrm{t}} \mathrm{BD}^{3}-2355.2 \mathrm{f}_{\mathrm{t}} \mathrm{BD}^{2}+3304.1 \mathrm{f}_{\mathrm{t}} \mathrm{BD}-1542.5 \mathrm{f}_{\mathrm{t}}$

$645 \mathrm{f}_{\mathrm{c}, \mathrm{SBF}}=-2.0029 \mathrm{f}_{\mathrm{t}} \mathrm{BD}^{2}+7.08 \mathrm{f}_{\mathrm{t}} \mathrm{BD}-4.2166 \mathrm{f}_{\mathrm{t}}$

646 At 180 days,

$647 \quad \mathrm{BD}_{\mathrm{CFF}}=-0.022 \mathrm{~W}_{\mathrm{f}}+1.517$

$648 \quad \mathrm{BD}_{\mathrm{SBF}}=-0.024 \mathrm{~W}_{\mathrm{f}}+1.568$

649 Such that,

$650 \mathrm{f}_{\mathrm{c}, \text { CFF }}=1010.7 \mathrm{f}_{\mathrm{t}} \mathrm{BD}^{3}-4207.4 \mathrm{f}_{\mathrm{t}} \mathrm{BD}^{2}+5831.5 \mathrm{f}_{\mathrm{t}} \mathrm{BD}-2689.7 \mathrm{f}_{\mathrm{t}}$

$651 \mathrm{f}_{\mathrm{c}, \mathrm{SBF}}=-0.8468 \mathrm{f}_{\mathrm{t}} \mathrm{BD}^{2}+3.270 \mathrm{f}_{\mathrm{t}} \mathrm{BD}-1.103 \mathrm{f}_{\mathrm{t}}$

652 The proposed relationships between bulk density, compressive and tensile strength takes into 653 account the fibre type and fibre weight fraction along with fibre degradation with time. These 654 relationships based on experimental work carried out on 525 samples for each fibre. Such 655 empirical models are important tools for predicting any one of properties of $\mathrm{CFF} / \mathrm{SBF}$ 656 reinforced soil bricks. These models, therefore, reduces the volume of laboratory experiment 657 required. 

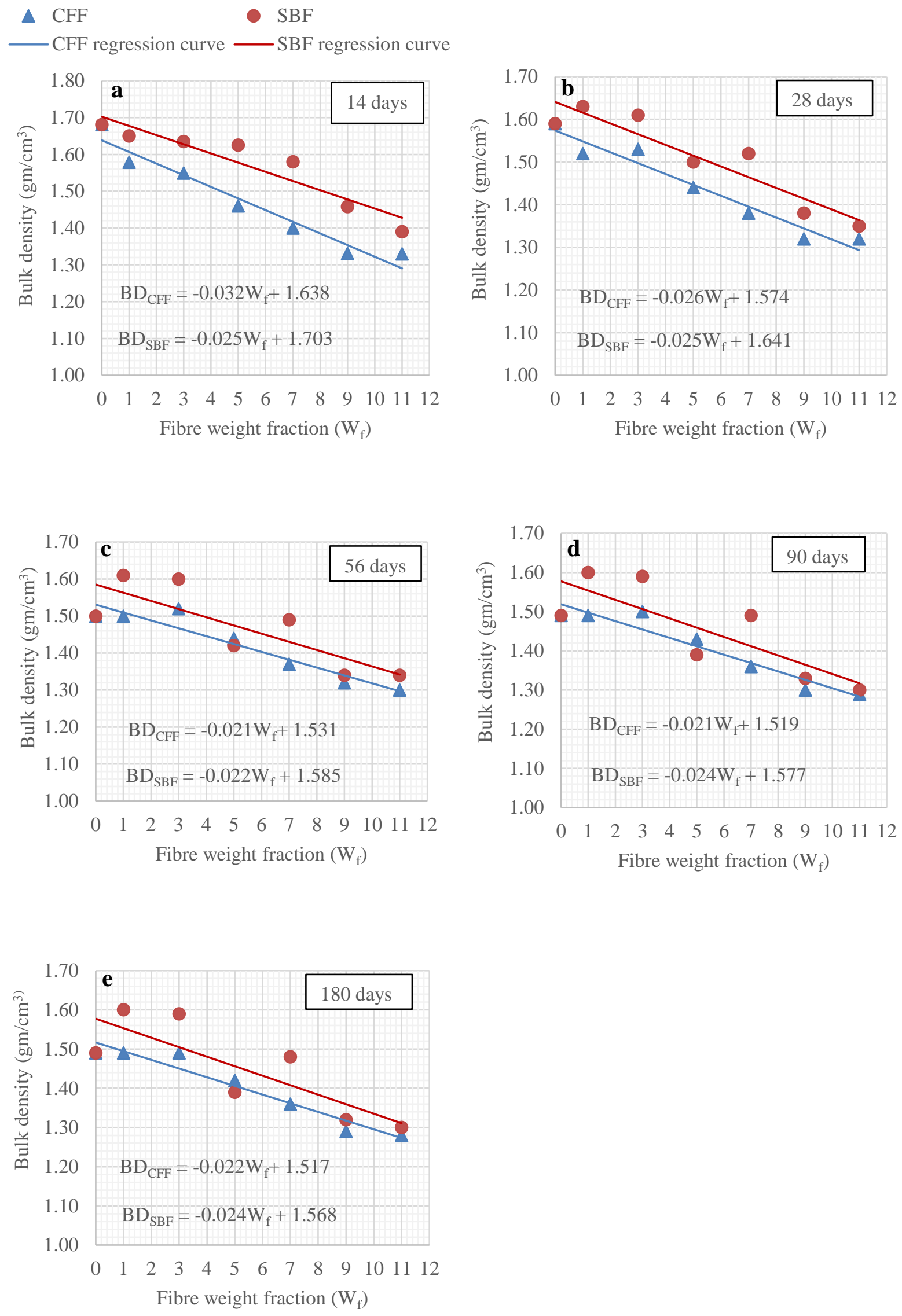

665 Figure 27: Bulk density vs CFF/SBF fibre weight fraction at 14, 28, 56, 90, 180 days. 

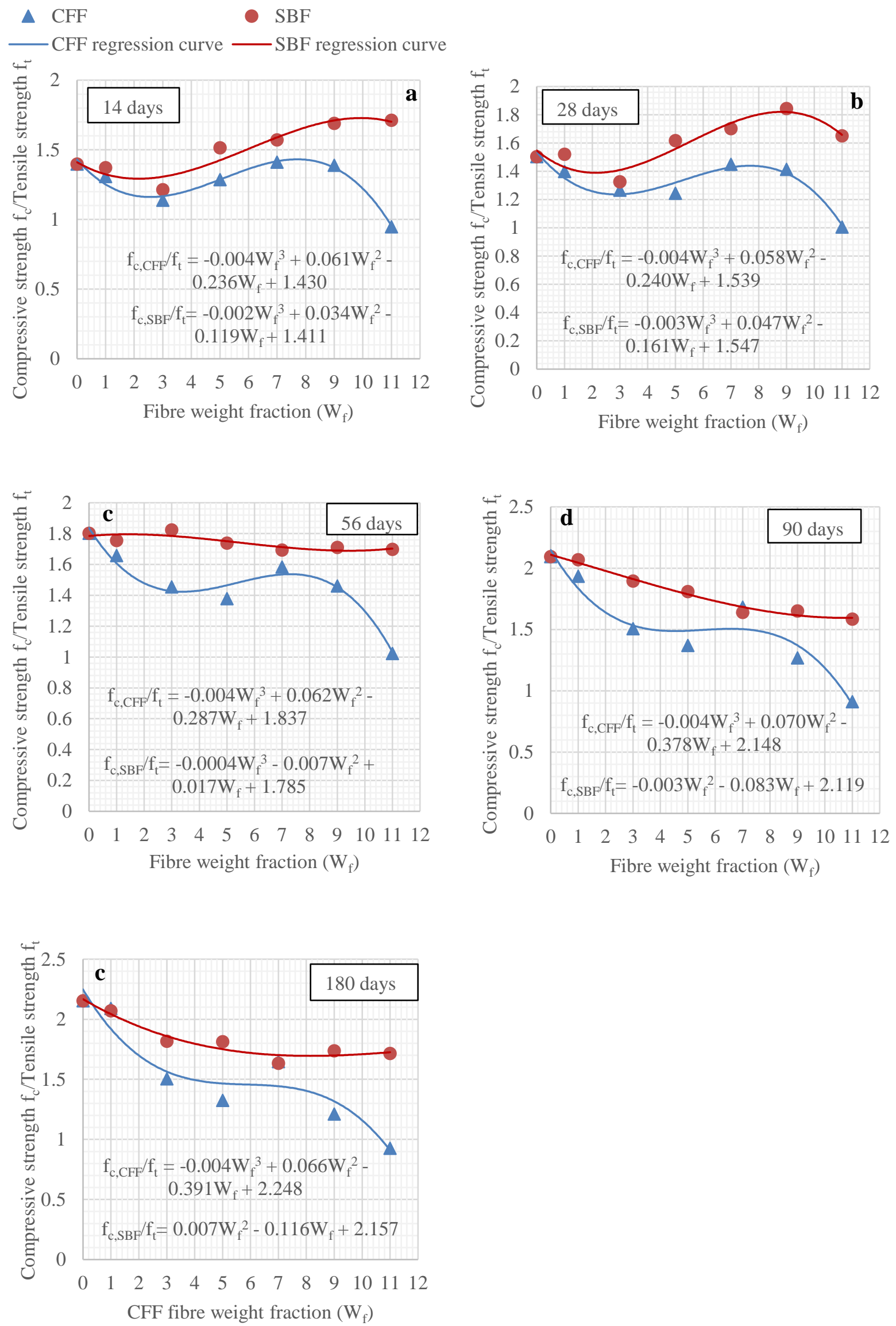

678 Figure 28: Ratio of compressive strength and tensile strength vs CFF/SBF weight fraction. 
679 Also, the relationships between the compressive and tensile strength of CFF-soil bricks at 14, 28, 56, 90 and 180 days were derived via nonlinear curve fitting as shown in Figure 29;

681

$\mathrm{f}_{\mathrm{c}, 14, \mathrm{CFF}}=1.759 \mathrm{f}_{\mathrm{t}}^{2}-4.652 \mathrm{f}_{\mathrm{t}}+4.700$

682

$\mathrm{f}_{\mathrm{c}, 28, \mathrm{CFF}}=2.318 \mathrm{f}_{\mathrm{t}}^{2}-7.586 \mathrm{f}_{\mathrm{t}}+8.305$

683

$\mathrm{f}_{\mathrm{c}, 56, \mathrm{CFF}}=4.809 \mathrm{ft}^{2}-18.530 \mathrm{ft}+20.430$

684

$\mathrm{f}_{\mathrm{c}, 90, \mathrm{CFF}}=6.319 \mathrm{f}_{\mathrm{t}}^{2}-26.725 \mathrm{f}_{\mathrm{t}}+30.972$

685

$\mathrm{f}_{\mathrm{c}, 180, \mathrm{CFF}}=6.688 \mathrm{f}_{\mathrm{t}}^{2}-27.998 \mathrm{f}_{\mathrm{t}}+31.919$

686

In order to find a general empirical equation for compressive and tensile strength of CFF

687 reinforced soil bricks, the average of above five equations (equations $6 \mathrm{a}-6 \mathrm{e}$ ) is calculated;

688

$\mathrm{f}_{\mathrm{c}, \mathrm{CFF}, \text { avg }}=4.379 \mathrm{f}_{\mathrm{t}}^{2}-17.098 \mathrm{f}_{\mathrm{t}}+19.265$

689

Where $\mathrm{f}_{\mathrm{c}}, \mathrm{CFF}$, avg is average compressive strength of CFF reinforced soil bricks which is a

690 function of CFF weight fraction in soil bricks. The proposed constitutive equation explains well

691 the experimental behavior of CFF reinforced soil bricks as a satisfactory overall coefficient of 692 determination $\mathrm{R}^{2}=0.917$ was achieved. Similarly, a simple correlation for compressive and 693 tensile strength of SBF reinforced soil brick can be established;

694

$\mathrm{f}_{\mathrm{c}, 14, \mathrm{SBF}}=-1.956 \mathrm{f}_{\mathrm{t}}^{2}+7.592 \mathrm{f}_{\mathrm{t}}-4.619$

695

$\mathrm{f}_{\mathrm{c}, 28, \mathrm{SBF}}=-4.396 \mathrm{f}_{\mathrm{t}}^{2}+16.632 \mathrm{f}_{\mathrm{t}}-12.673$

696

$\mathrm{f}_{\mathrm{c}, 56, \mathrm{SBF}}=2.479 \mathrm{f}_{\mathrm{t}}^{2}-7.721 \mathrm{f}_{\mathrm{t}}+8.930$

$697 \quad \mathrm{f}_{\mathrm{c}, 90, \mathrm{SBF}}=10.010 \mathrm{f}_{\mathrm{t}}^{2}-38.063 \mathrm{f}_{\mathrm{t}}+39.281$

698

$\mathrm{f}_{\mathrm{c}, 180, \mathrm{SBF}}=1.096 \mathrm{f}_{\mathrm{t}}^{2}-2.575 \mathrm{f}_{\mathrm{t}}+4.357$

699 And the average compressive strength of SBF reinforced soil bricks $\mathrm{f}_{\mathrm{c}, \mathrm{SBF}}$, avg is obtained with $700 \quad$ coefficient of determination $\mathrm{R}^{2}=0.899$;

701

$\mathrm{f}_{\mathrm{c}, \mathrm{SBF}, \text { avg }}=1.447 \mathrm{f}_{\mathrm{t}}^{2}-4.827 \mathrm{f}_{\mathrm{t}}+7.055$ 

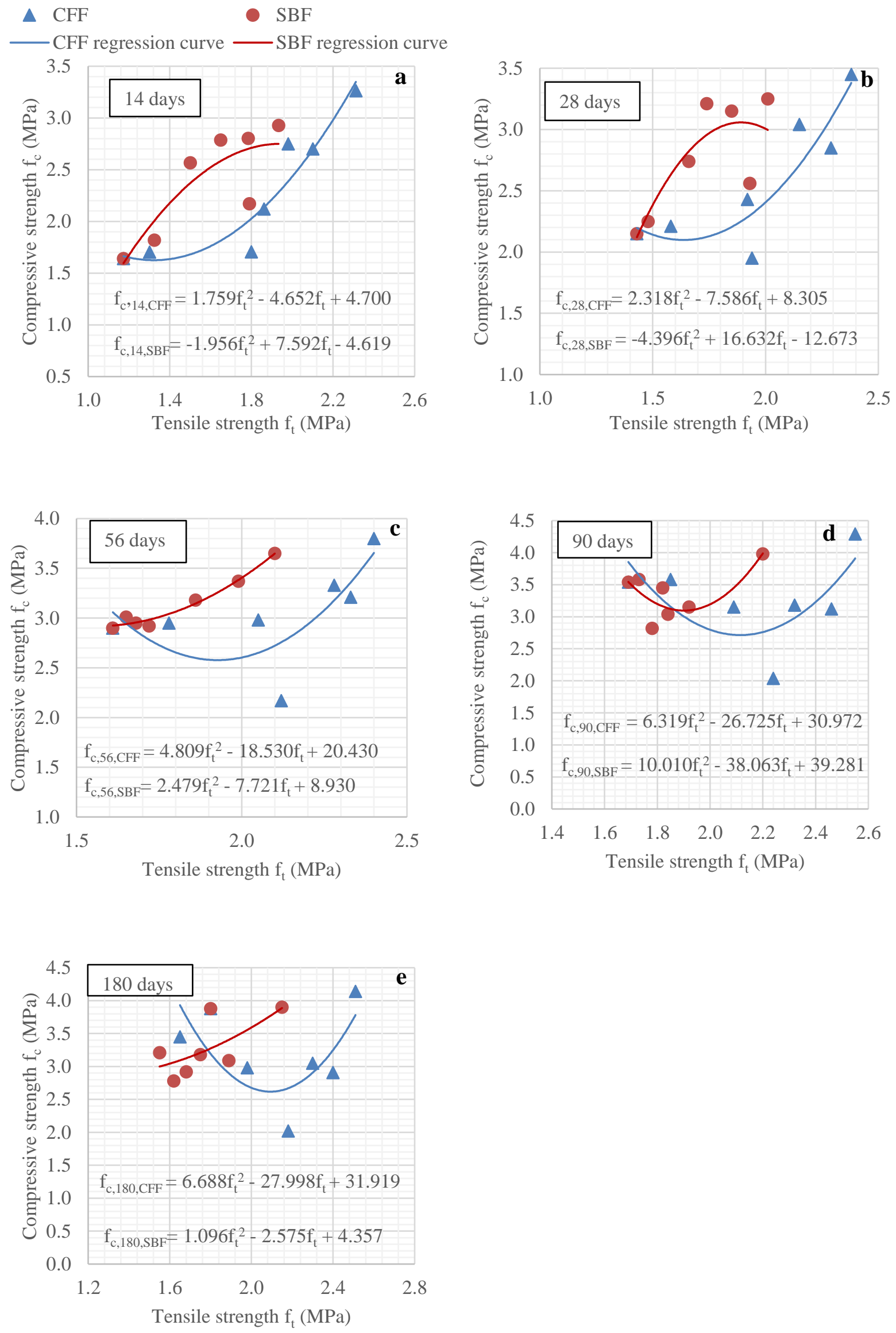

Figure 29: Compressive strength vs tensile strength at 14, 28, 56, 90 and 180 days. 
The relationship between compressive strength and tensile strength are recommended by building codes as useful and economical, particularly for preliminary investigations. The proposed compressive-tensile strength relationship in equations 7 and 9 can be used to estimate the compressive strength of CFF reinforced soil bricks and SBF reinforced soil bricks respectively, using the value of tensile strength and vice versa. These two equations do not consider the aging effect of the samples.

\subsection{Response surface models of soil brick properties}

Using Response Surface Methodology (RSM) on Matlab R2016a software, response surface models that fully predict all soil brick properties were developed. These models consider some key variables; fibre type, fibre weight friction, effect of brick aging, compressive strength, tensile strength, bulk density and water absorption. Based on regression coefficients at $95 \%$ confidence level, the response surface equations for compressive strength in MPa (equation 10), tensile strength in MPa (equation 11), bulk density in $\mathrm{gm} / \mathrm{cm}^{3}$ (equation 12) and water absorption in percentage (equation 13) were established as polynomial models as shown in Figures $30-37$.

$f_{c}(x, y)=\alpha_{0}+\alpha_{1} x+\alpha_{2} y+\alpha_{3} x^{2}+\alpha_{4} x y+\alpha_{5} y^{2}+\alpha_{6} x^{2} y+\alpha_{7} x y^{2}+\alpha_{8} y^{3}+\alpha_{9} x^{2} y^{2}+\alpha_{10} x y^{3}$

$$
+\alpha_{11} \mathrm{y}^{4}
$$

$f_{t}(x, y)=\beta_{0}+\beta_{1} x+\beta_{2} y+\beta_{3} x^{2}+\beta_{4} x y+\beta_{5} y^{2}+\beta_{6} x^{2} y+\beta_{7} x y^{2}+\beta_{8} y^{3}$

$B D(x, y)=k_{0}+k_{1} x+k_{2} y+k_{3} x^{2}+k_{4} x y+k_{5} y^{2}+k_{6} x^{2} y+k_{7} x y^{2}+k_{8} y^{3}$

$W A(x, y)=q_{0}+q_{1} x+q_{2} y+q_{3} x y+q_{4} y^{2}$

Where $\mathrm{x}$ is the response variable of fibre weight fraction in percentage; $\mathrm{y}$ is the response variable of samples age in days; $\alpha, \beta, \mathrm{k}$ and $\mathrm{q}$ are non-dimensional interaction coefficients for the models predicting compressive strength, tensile strength, bulk density and water absorption respectively. 


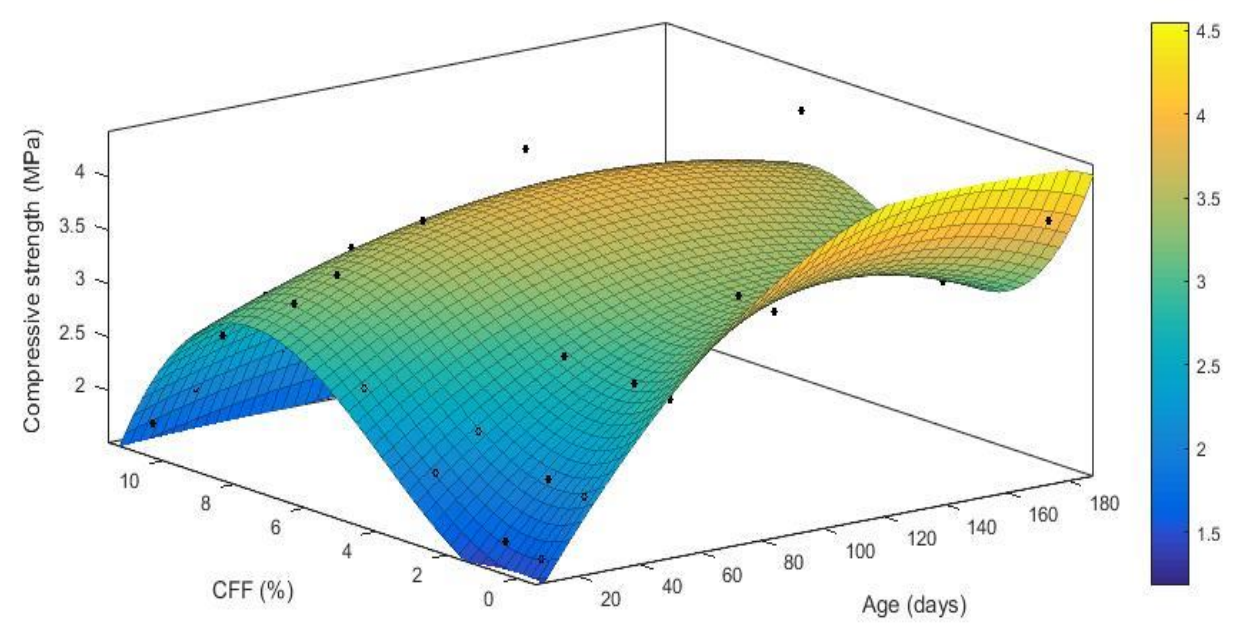

734 Figure 30: Response Surface plot of compressive strength vs \% CFF and age of samples.

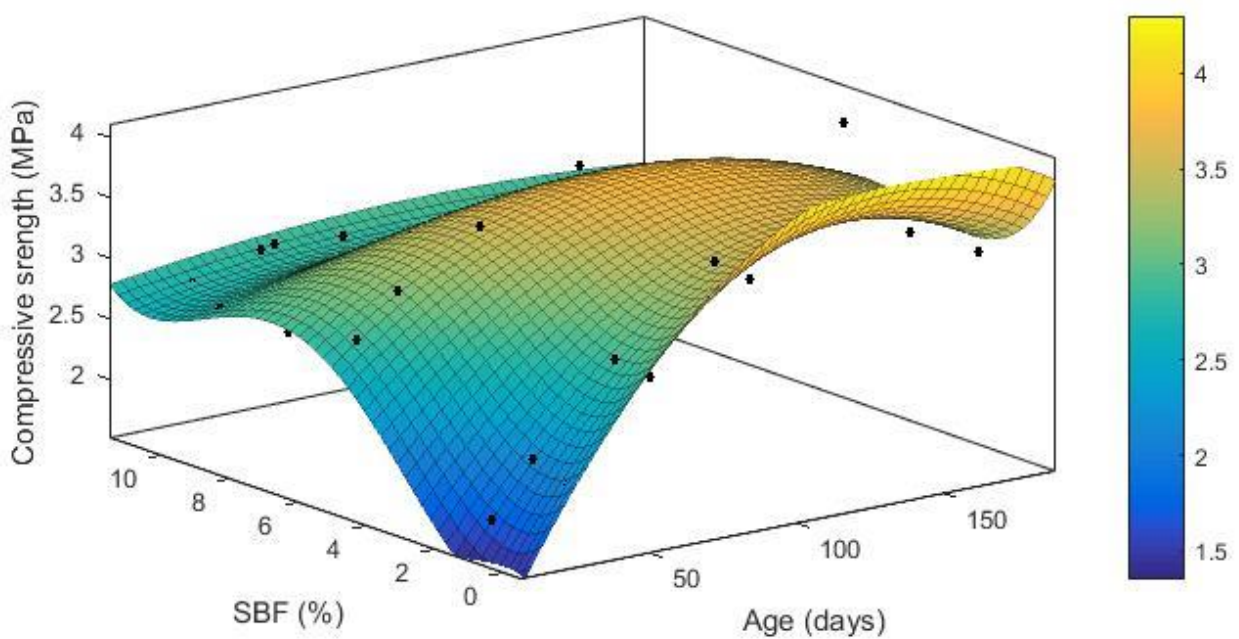

735 Figure 31: Response Surface plot of compressive strength vs \% SBF and age of samples.

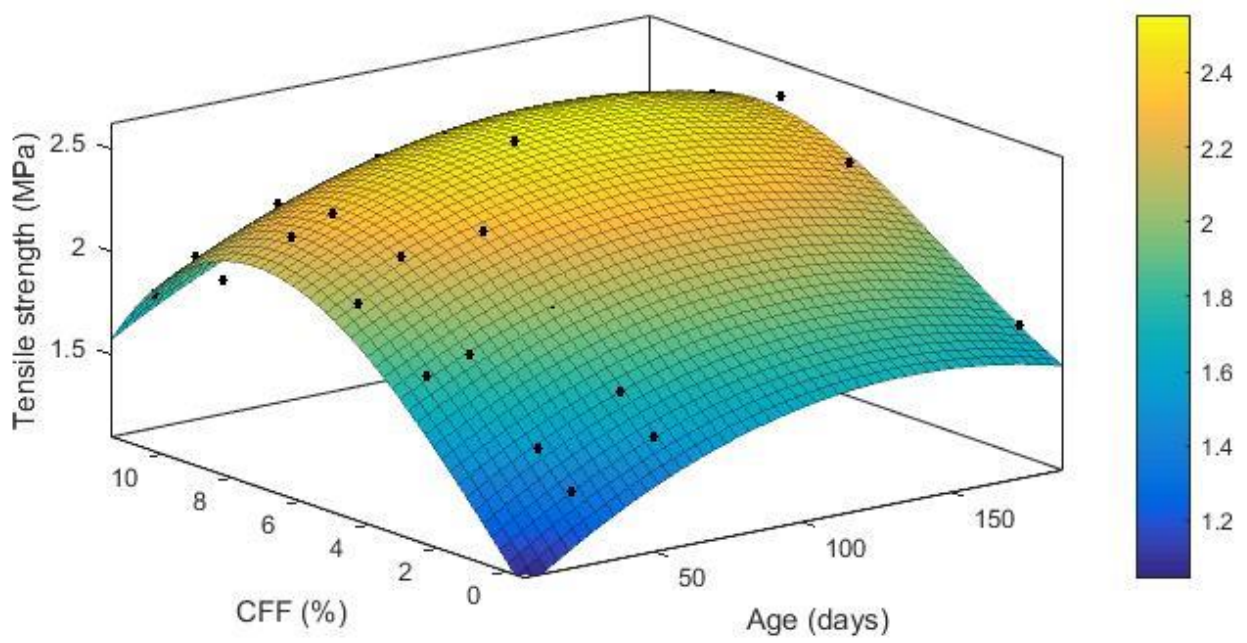

Figure 32: Response Surface plot of tensile strength vs \% CFF and age of samples. 


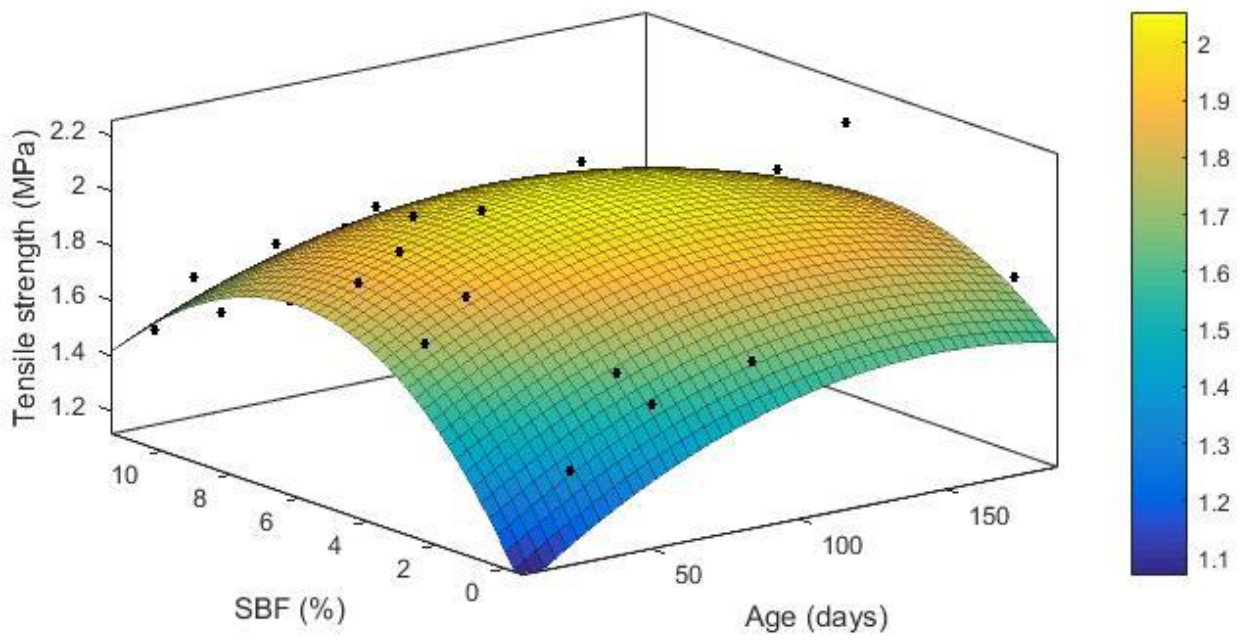

737

Figure 33: Response Surface plot of tensile strength vs \% SBF and age of samples.

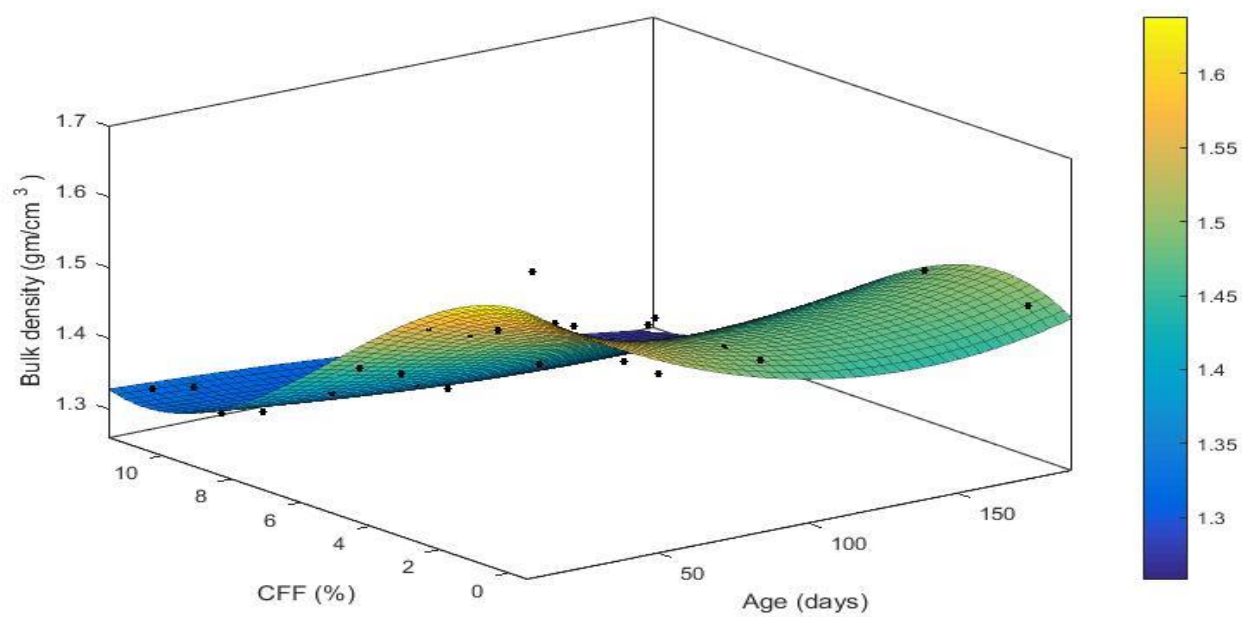

Figure 34: Response Surface plot of bulk density vs \% CFF and age of samples.

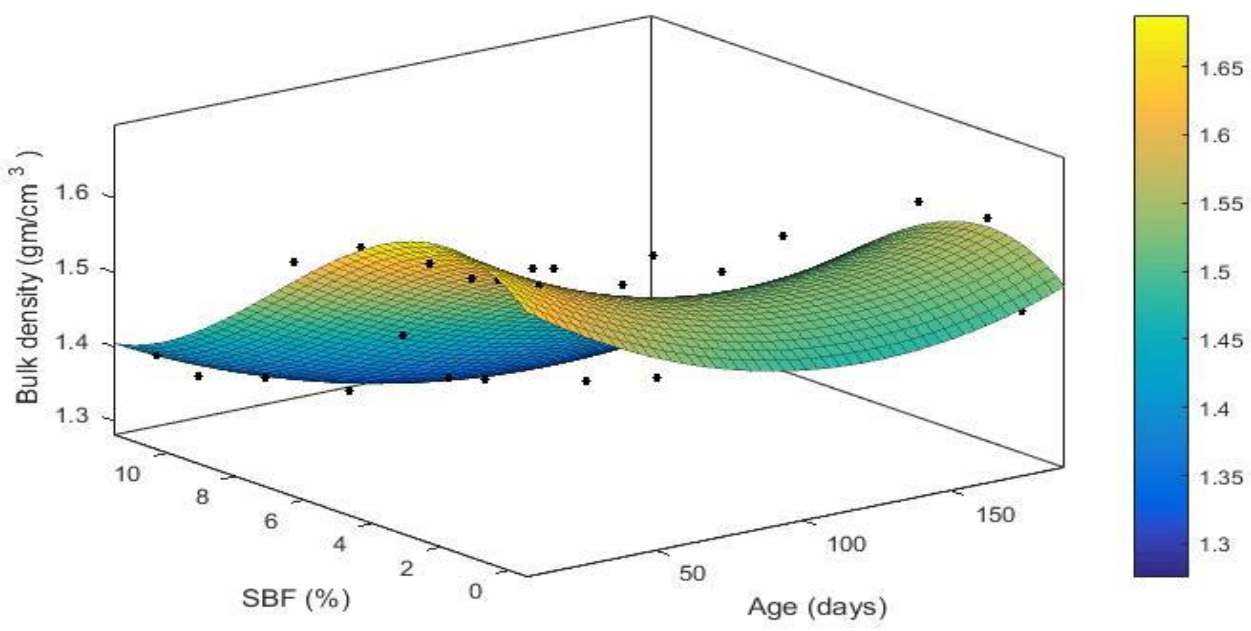

Figure 35: Response Surface plot of bulk density vs \% SBF and age of samples. 


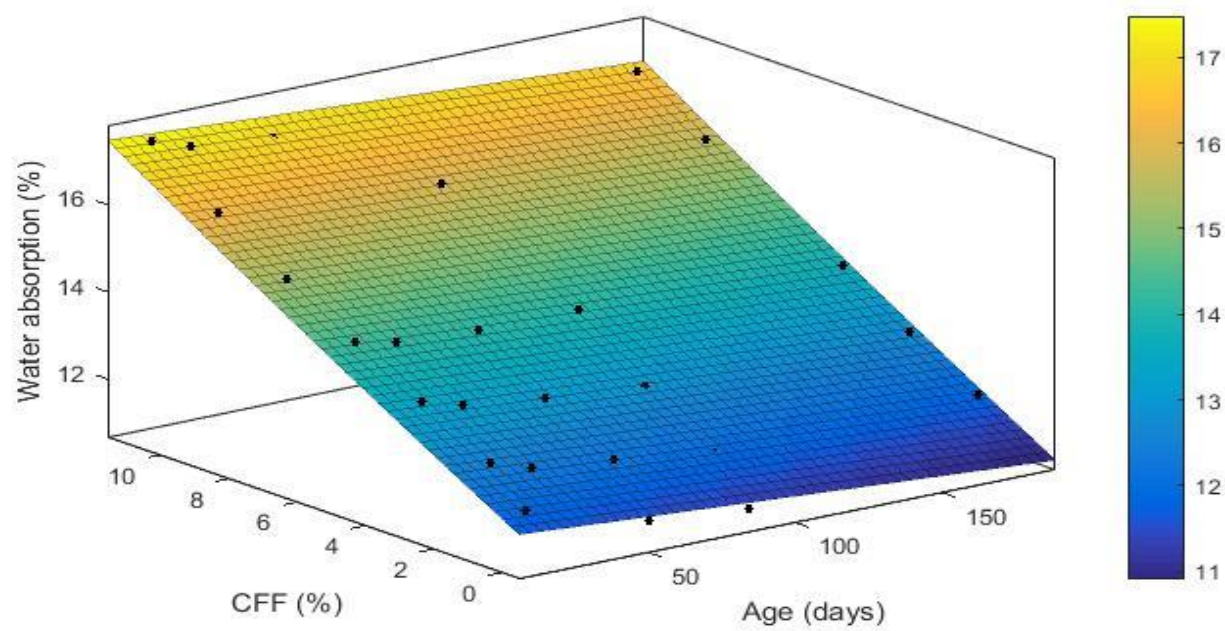

Figure 36: Response Surface plot of water absorption vs \% CFF and age of samples.

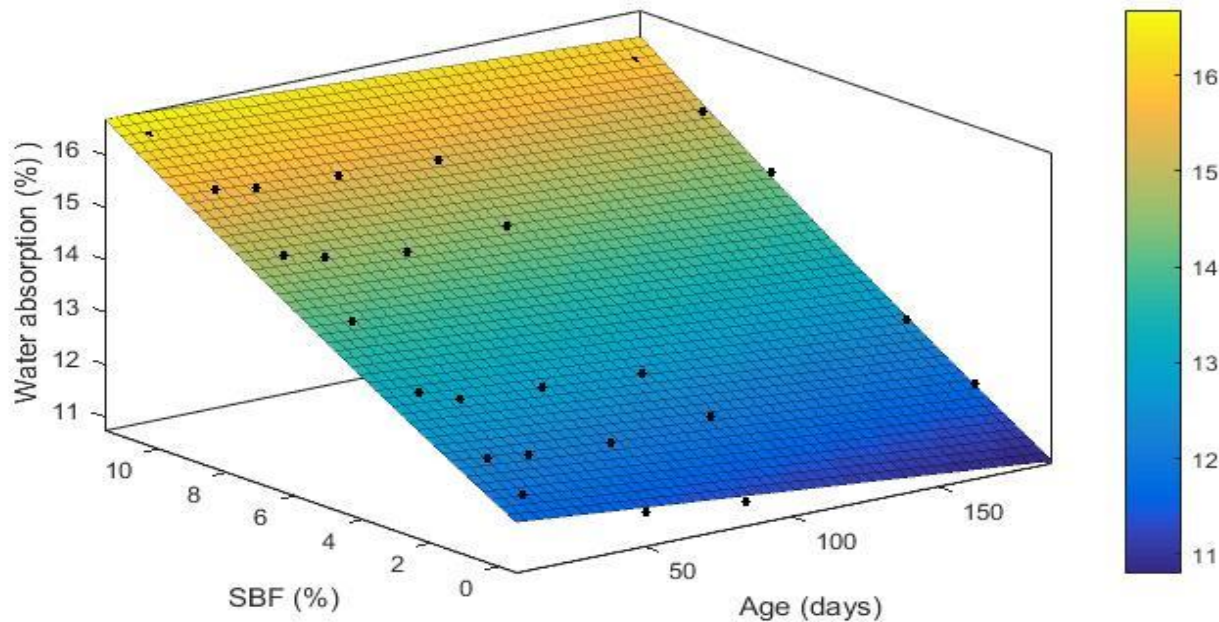

Figure 37: Response Surface plot of water absorption vs \% SBF and age of samples.

742 The proposed response models can be applied for CFF-soil bricks and SBF-soil bricks based

743 on the values of interaction coefficients $\alpha, \beta, \mathrm{k}$ and q given in Tables 7 and 8 respectively.

744 Similar constitutive relationship for oil palm broom fibres reinforced concrete has been

745 proposed by Momoh et al. [47].

The key aspect of any regression model is the error rates because this measures its predictive capacity. The success of regression analysis lies in the adequacy of the fitted model to predict values close to the observed data values. Two statistical coefficients, Root Mean Square Error (RMSE) and coefficient of determination $\left(\mathrm{R}^{2}\right)$, were used to assess how well the developed 
response models predict the behaviour of reinforced soil bricks, including its compressive strength $\left(\mathrm{f}_{\mathrm{c}}\right)$, tensile strength $\left(\mathrm{f}_{\mathrm{t}}\right)$, bulk density $(\mathrm{BD})$ and water absorption (WA) similar to Momoh et al. [47].

Root Mean Square Error (RMSE) is widely used to measure the differences between observed values and those predicted by a model in order to quantify the model performance. RMSE is always non-negative, and a value of 0 would indicate a perfect fit to the data. In general, the closer the RMSE is to a value of 0 the better. Coefficient of determination $\left(\mathrm{R}^{2}\right)$ is a measure of the degree of correlation between two variables used in assessing the goodness of fit. It provides a measure of how well observed outcomes are replicated by the model and ranges between 0 and 1 , with a value of 1 indicating perfect fit. In this study, it measures how well the model fits the experimental data. The values of the coefficient of determination $\mathrm{R}^{2}$ and Root Mean Square Error (RMSE) presented in Tables 7 and 8 indicate a good correlation between the experimental data and the models. This proves the suitability of proposed models for practical engineering applications. However, it is recommended not to use these models beyond 180 days and not to exceed $11 \%$ fibre weight fraction as these models are based on experimental data between 14 and 180 days and $11 \%$ maximum fibre content.

Care should be taken in using density model for SBF-soil bricks as their coefficient of determination $\mathrm{R}^{2}$ is low as 0.8367 . However, when data points of low fraction (3\%) are removed, $\mathrm{R}^{2}$ value improves to 0.916 . 
773 Table 7: Response surface coefficient for predicting properties of CFF reinforced soil bricks.

\begin{tabular}{|c|c|c|c|c|}
\hline Property & $\begin{array}{c}\text { Regression Coefficients } \\
\text { (with } 95 \% \text { confidence } \\
\text { bound) }\end{array}$ & Value & $\mathbf{R}^{2}$ & $\begin{array}{l}\text { Root Mean } \\
\text { Square Error } \\
\text { (RMSE) }\end{array}$ \\
\hline \multirow[t]{2}{*}{ Compressive } & $\alpha_{0}$ & 1.121 & 0.917 & 0.245 \\
\hline & $\alpha_{1}$ & 0.04143 & & \\
\hline \multirow[t]{10}{*}{ strength $\left(\mathrm{f}_{\mathrm{c}}\right)$} & $\alpha_{2}$ & 0.02657 & & \\
\hline & $\alpha_{3}$ & -0.0001436 & & \\
\hline & $\alpha_{4}$ & -0.007056 & & \\
\hline & $\alpha_{5}$ & 0.09519 & & \\
\hline & $\alpha_{6}$ & $1.45 \mathrm{e}-05$ & & \\
\hline & $\alpha_{7}$ & 0.0006654 & & \\
\hline & $\alpha_{8}$ & -0.00952 & & \\
\hline & $\alpha_{9}$ & $-4.909 e-07$ & & \\
\hline & $\alpha_{10}$ & $-2.642 \mathrm{e}-05$ & & \\
\hline & $\alpha_{11}$ & $9.507 \mathrm{e}-05$ & & \\
\hline \multirow[t]{2}{*}{ Tensile } & $\beta_{0}$ & 1.104 & 0.9564 & 0.08352 \\
\hline & $\beta_{1}$ & 0.01017 & & \\
\hline \multirow[t]{7}{*}{ strength $\left(\mathrm{f}_{\mathrm{t}}\right)$} & $\beta_{2}$ & 0.2154 & & \\
\hline & $\beta_{3}$ & $-3.858 \mathrm{e}-05$ & & \\
\hline & $\beta_{4}$ & -0.0008032 & & \\
\hline & $\beta_{5}$ & -0.001298 & & \\
\hline & $\beta_{6}$ & $8.206 \mathrm{e}-07$ & & \\
\hline & $\beta_{7}$ & $5.865 \mathrm{e}-05$ & & \\
\hline & $\beta_{8}$ & -0.001234 & & \\
\hline \multirow[t]{2}{*}{ Bulk density } & $\mathrm{k}_{0}$ & 1.652 & 0.9638 & 0.0222 \\
\hline & $\mathrm{k}_{1}$ & -0.002791 & & \\
\hline \multirow[t]{7}{*}{ (BD) } & $\mathrm{k}_{2}$ & -0.01048 & & \\
\hline & $\mathrm{k}_{3}$ & $1.028 \mathrm{e}-05$ & & \\
\hline & $\mathrm{k}_{4}$ & 0.0003696 & & \\
\hline & $\mathrm{k}_{5}$ & -0.006878 & & \\
\hline & $\mathrm{k}_{6}$ & $-9.941 e-07$ & & \\
\hline & $\mathrm{k}_{7}$ & $-1.221 \mathrm{e}-05$ & & \\
\hline & $\mathrm{k}_{8}$ & 0.0004646 & & \\
\hline \multirow{2}{*}{ Water } & $\mathrm{q}_{0}$ & 11.98 & 0.961 & 0.400 \\
\hline & $q_{1}$ & -0.004373 & & \\
\hline \multirow[t]{2}{*}{ absorption } & $\mathrm{q}_{2}$ & 0.4518 & & \\
\hline & $\mathrm{q}_{3}$ & $4.72 \mathrm{e}-05$ & & \\
\hline (WA) & $\mathrm{q}_{4}$ & 0.002308 & & \\
\hline
\end{tabular}

774 
Table 8: Response surface coefficient for predicting properties of SBF reinforced soil bricks.

\begin{tabular}{|c|c|c|c|c|}
\hline Property & $\begin{array}{c}\text { Regression Coefficients } \\
\text { (with } 95 \% \text { confidence } \\
\text { bound) }\end{array}$ & Value & $\mathbf{R}^{2}$ & $\begin{array}{l}\text { Root Mean } \\
\text { Square Error } \\
\quad(\text { RMSE) }\end{array}$ \\
\hline \multirow[t]{2}{*}{ Compressive } & $\alpha_{0}$ & 1.125 & 0.9052 & $0.2036)$ \\
\hline & $\alpha_{1}$ & 0.04157 & & \\
\hline \multirow{10}{*}{ strength $\left(\mathrm{f}_{\mathrm{c}}\right)$} & $\alpha_{2}$ & -0.04228 & & \\
\hline & $\alpha_{3}$ & -0.0001511 & & \\
\hline & $\alpha_{4}$ & -0.005102 & & \\
\hline & $\alpha_{5}$ & 0.1782 & & \\
\hline & $\alpha_{6}$ & $1.497 \mathrm{e}-05$ & & \\
\hline & $\alpha_{7}$ & 0.0001413 & & \\
\hline & $\alpha_{8}$ & $-0.02799)$ & & \\
\hline & $\alpha_{9}$ & $-2.896 e-07$ & & \\
\hline & $\alpha_{10}$ & $1.511 \mathrm{e}-06$ & & \\
\hline & $\alpha_{11}$ & 0.001207 & & \\
\hline \multirow[t]{2}{*}{ Tensile } & $\beta_{0}$ & 1.152 & 0.8564 & 0.1238 \\
\hline & $\beta_{1}$ & 0.007806 & & \\
\hline \multirow[t]{7}{*}{ strength $\left(\mathrm{f}_{\mathrm{t}}\right)$} & $\beta_{2}$ & 0.222 & & \\
\hline & $\beta_{3}$ & $-2.793 e-05$ & & \\
\hline & $\beta_{4}$ & -0.000684 & & \\
\hline & $\beta_{5}$ & -0.02126 & & \\
\hline & $\beta_{6}$ & $3.811 \mathrm{e}-07$ & & \\
\hline & $\beta_{7}$ & $4.073 e-05$ & & \\
\hline & $\beta_{8}$ & 0.0003255 & & \\
\hline \multirow[t]{2}{*}{ Bulk density } & $\mathrm{k}_{0}$ & 1.676 & 0.8367 & 0.05414 \\
\hline & $\mathrm{k}_{1}$ & -0.002836 & & \\
\hline \multirow[t]{7}{*}{ (BD) } & $\mathrm{k}_{2}$ & 0.0332 & & \\
\hline & $\mathrm{k}_{3}$ & $1.139 \mathrm{e}-05$ & & \\
\hline & $\mathrm{k}_{4}$ & $3.71 \mathrm{e}-05$ & & \\
\hline & $\mathrm{k}_{5}$ & -0.01092 & & \\
\hline & $\mathrm{k}_{6}$ & $-2.702 e-07$ & & \\
\hline & $\mathrm{k}_{7}$ & $1.852 \mathrm{e}-06$ & & \\
\hline & $\mathrm{k}_{8}$ & 0.0005285 & & \\
\hline \multirow[t]{2}{*}{ Water } & $\mathrm{q}_{0}$ & 11.95 & 0.9232 & 0.505 \\
\hline & $\mathrm{q}_{1}$ & -0.004925 & & \\
\hline \multirow[t]{2}{*}{ absorption } & $\mathrm{q}_{2}$ & 0.3734 & & \\
\hline & $\mathrm{q}_{3}$ & 0.0001759 & & \\
\hline (WA) & $\mathrm{q}_{4}$ & 0.003328 & & \\
\hline
\end{tabular}


Stress-strain relation was obtained at 14 days, as approximate representations of the stressstrain curves of fibre reinforced soil bricks, according to the recommendations in British Standard EN 1052-2:2016 [28]. Such stress-strain curves $(\sigma-\epsilon)$ express essential information about the mechanical properties of natural fibre soil bricks. The stress-strain relations of the unreinforced and fibre reinforced soil bricks are given in Figures 38 and 39. The models represent the behaviour of fibre reinforced soil bricks under compression.

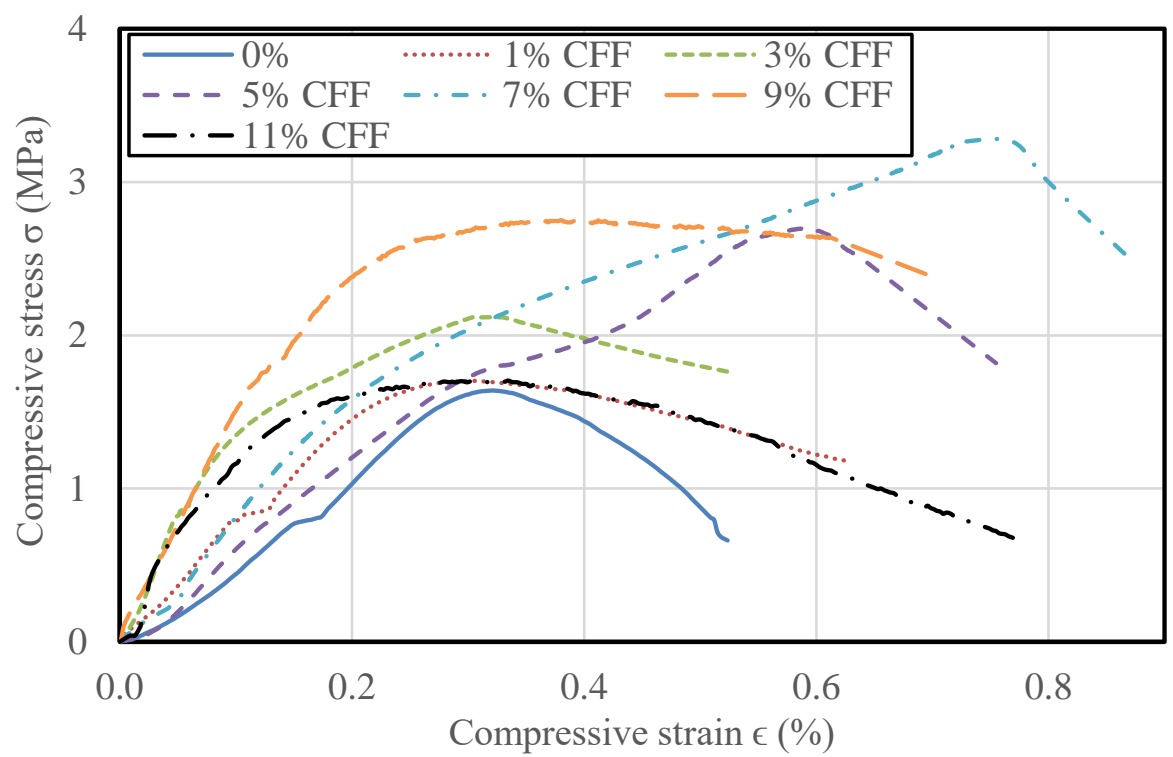

Figure 38: Compression stress-strain curves for unreinforced and CFF reinforced soil bricks.

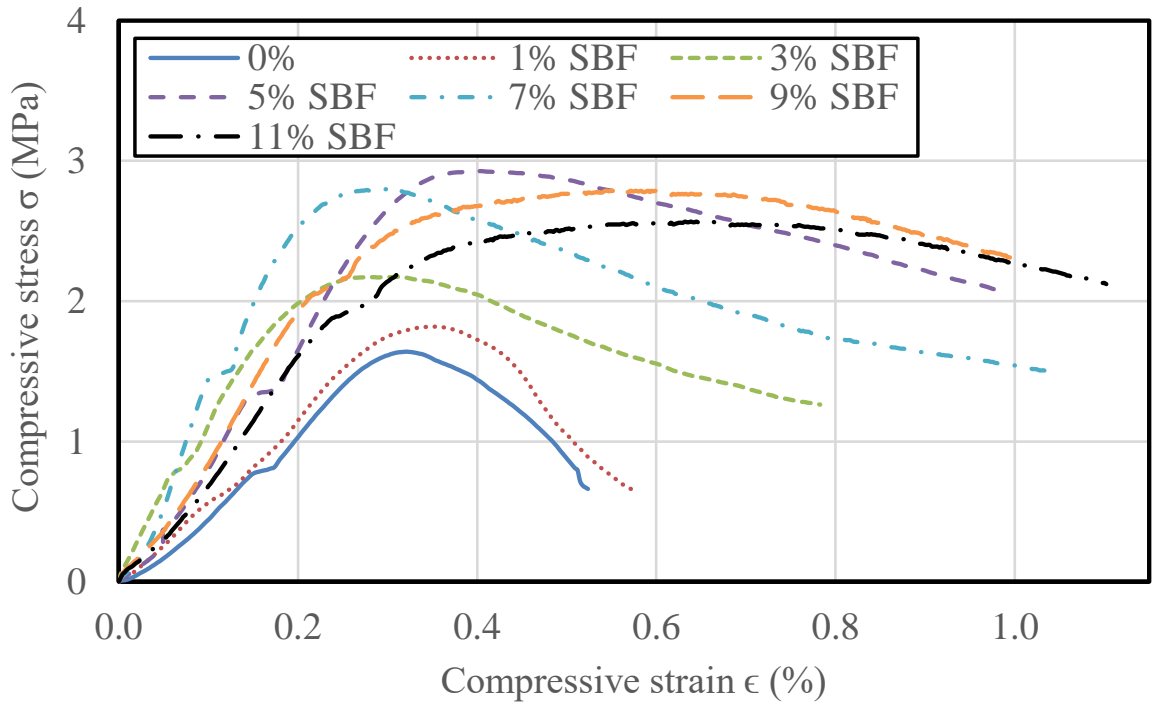

Figure 39: Compression stress-strain curves for unreinforced and SBF reinforced soil bricks. 
Based on the proposed stress-strain relations, the mechanical parameters for CFF-soil bricks and SBF-soil bricks were calculated. The mean value of yield stress $\sigma_{\mathrm{y}}$, strain at yield $\epsilon_{\mathrm{y}}$, residual stress $\sigma_{\text {res }}$, ultimate strain $\epsilon_{\mathrm{u}}$, strain ductility $\mu^{\epsilon}$ and secant Young's modulus $E_{1 / 3}$ are presented in Tables 9 and 10 as well as their Standard Deviation (SD) and Coefficient of Variation $(\mathrm{CV})$.

Yield stress, corresponding strain at yield and secant Young's modulus represents the rising branch of the stress-strain curve, while residual stress, ultimate strain and strain ductility factor $812\left(\epsilon_{\mathrm{u}} / \epsilon_{\text {peak }}\right)$ are associated with post-peak softening branch. The stiffness or secant Young's modulus was also calculated from the obtained results. The British Standard EN 1052-2:2016 define a secant modulus, $\mathrm{E}_{\mathrm{s}}$, as Young's modulus corresponding to a normal stress equal to one-third of the peak strength [28]. These parameters are useful to support the numerical modeling of the behavior of natural fibre soil bricks and can support the validation of the results

817 of experimental tests of future studies.

818 Table 9: Yield stress, strains, strain ductility and secant Young's modulus for CFF-soil bricks.

\begin{tabular}{cccccccc}
\hline & $\begin{array}{c}\boldsymbol{\sigma}_{\mathbf{y}} \\
(\mathbf{M P a})\end{array}$ & $\begin{array}{c}\boldsymbol{\sigma}_{\text {res }} \\
(\mathbf{M P a})\end{array}$ & $\boldsymbol{\sigma}_{\text {Yield }} / \boldsymbol{\sigma}_{\text {res }}$ & $\boldsymbol{\epsilon}_{\mathbf{y}}$ & $\boldsymbol{\epsilon}_{\mathbf{u}}$ & $\boldsymbol{\mu}^{\mathbf{\epsilon}}$ & $\begin{array}{c}\mathbf{E}_{\mathbf{1} / \mathbf{3}} \\
(\mathbf{M P a})\end{array}$ \\
\hline Mean & 1.25 & 1.57 & 0.96 & 0.15 & 0.68 & 5.58 & 1055 \\
SD & 0.45 & 0.76 & 0.58 & 0.09 & 0.13 & 2.78 & 491 \\
CV $(\%)$ & 35.70 & 48.24 & 60.34 & 58.46 & 19.02 & 49.72 & 46.59 \\
\hline
\end{tabular}

Table 10: Yield stress, strains, strain ductility and secant Young's modulus for SBF-soil bricks.

\begin{tabular}{cccccccc}
\hline & $\begin{array}{c}\boldsymbol{\sigma}_{\mathbf{y}} \\
(\mathbf{M P a})\end{array}$ & $\begin{array}{c}\boldsymbol{\sigma}_{\text {res }} \\
(\mathbf{M P a})\end{array}$ & $\boldsymbol{\sigma}_{\text {Peak }} / \boldsymbol{\sigma}_{\text {res }}$ & $\begin{array}{c}\boldsymbol{\epsilon}_{\mathbf{y}} \\
(\boldsymbol{\%})\end{array}$ & $\begin{array}{c}\boldsymbol{\epsilon}_{\mathbf{u}} \\
(\boldsymbol{\%})\end{array}$ & $\boldsymbol{\mu}^{\boldsymbol{\epsilon}}$ & $\begin{array}{c}\mathbf{E}_{\mathbf{1} / \mathbf{3}} \\
(\mathbf{M P a})\end{array}$ \\
\hline Mean & 1.26 & 1.51 & 0.86 & 0.14 & 0.86 & 7.09 & 881 \\
SD & 0.57 & 0.69 & 0.20 & 0.06 & 0.23 & 3.91 & 333 \\
$\mathrm{CV}(\%)$ & 45.76 & 45.49 & 23.18 & 44.72 & 27.15 & 55.12 & 37.85 \\
\hline
\end{tabular}


Mean values of strain at yield of CFF reinforced soil bricks and SBF reinforced soil bricks are $0.15 \%$ and $0.14 \%$, which is close to the typical value of $0.20 \%$ assumed as strain at yield by masonry standards [48].

Stress-strain curves $(\sigma-\epsilon)$ were normalized with respect to yield stress $\sigma_{y}$ and the strain at yield $\epsilon_{\mathrm{y}}$ respectively and presented in Figures 40 and 41 for chicken feather fibres (CFF) and sugarcane bagasse fibres (SBF) reinforced soil bricks respectively. Design constitutive equations where stresses are normalized by the yield stress are often used because they can be adopted for different materials, regardless of their yield stress.

Based on the normalized stress-strain curves, the following closed-form design equations were derived:

$\bar{\sigma}_{\mathrm{CFF}}=-0.40 \bar{\varepsilon}^{3}+0.53 \bar{\varepsilon}^{2}+0.88 \bar{\varepsilon}$

$\bar{\sigma}_{\mathrm{SBF}}=-0.50 \bar{\varepsilon}^{3}+0.98 \bar{\varepsilon}^{2}+0.51 \bar{\varepsilon}$

For pre-yield $\bar{\varepsilon} \leq 1.0$ and,

$$
\bar{\sigma}_{\mathrm{CFF}}=0.03 \bar{\varepsilon}^{3}-0.34 \bar{\varepsilon}^{2}+1.42 \bar{\varepsilon}
$$

$\bar{\sigma}_{\mathrm{SBF}}=0.01 \bar{\varepsilon}^{3}-0.36 \bar{\varepsilon}^{2}+1.94 \bar{\varepsilon}$

For post-yield $1.0 \leq \bar{\varepsilon} \leq 4.7$

Where $\bar{\sigma}$ is normalised stress $\left(\sigma / \sigma_{\mathrm{y}}\right)$ and $\bar{\varepsilon}$ is normalised strain $\left(\epsilon / \epsilon_{\mathrm{y}}\right)$. The coefficient of determination $\left(\mathrm{R}^{2}\right)$ was found to range between 0.996 and 0.999 . The crossing point for equations $(14,16)$ and equations $(15,17)$ represent the point of yield, i.e. $\bar{\varepsilon}=1.0$. These polynomial equations were developed through an iterative procedure to ensure the continuity of the models at the crossing point $(\bar{\varepsilon}=1.0)$. Such equations are sufficiently simple to be used in engineering practice, allowing direct derivation of the stress-strain behaviour of fibre reinforced soil bricks. 


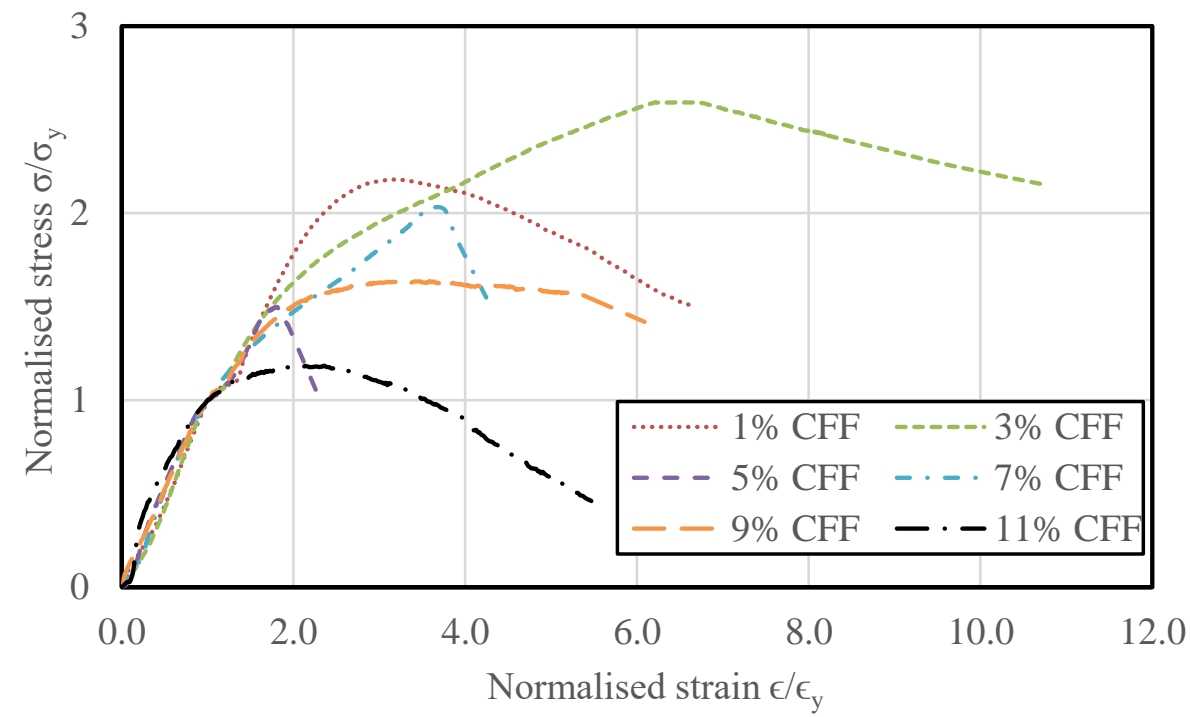

852

Figure 40: Normalized stress-strain curves for CFF reinforced soil bricks.

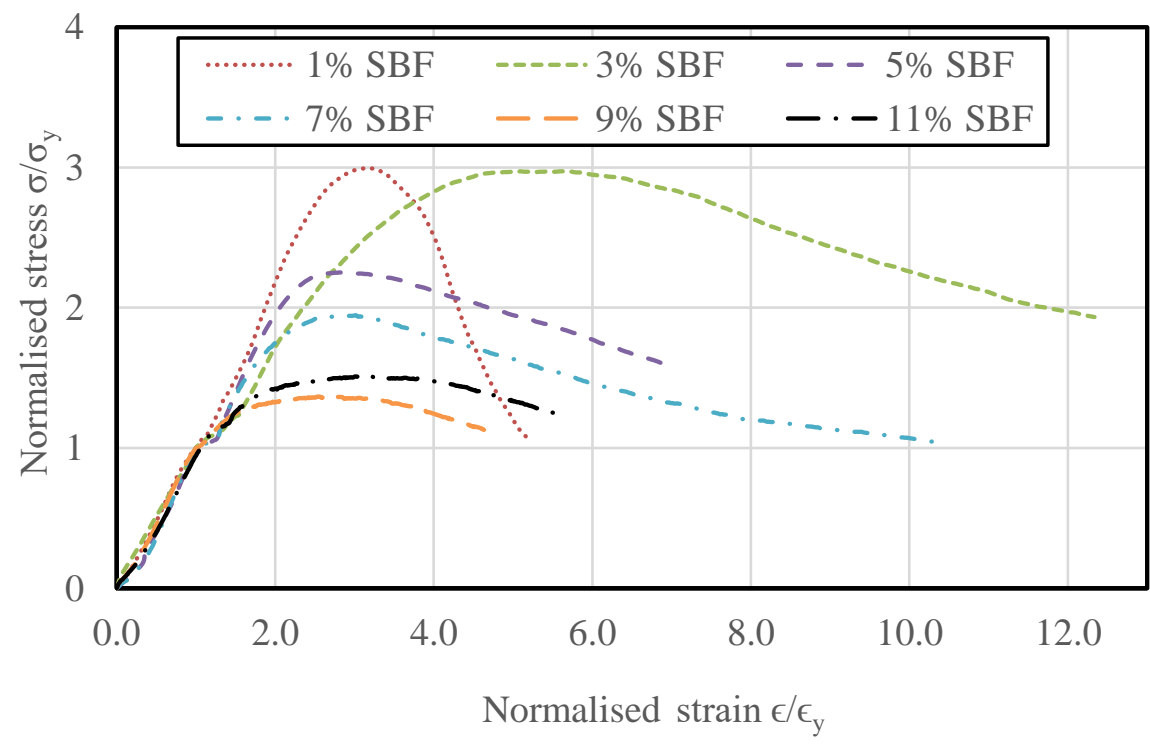

861

Figure 41: Normalized stress-strain curves for SBF reinforced soil bricks.

862 Mean values of normalized stress-strain curves presented in Figures 40 and 41 and the typical

863 mean normalized stress-strain curves for CFF reinforced soil bricks and SBF reinforced soil

864 bricks are presented in Figure 42.

865 The typical compression behaviour of CFF reinforced soil bricks and SBF reinforced soil bricks

866 can be generally classified with four significant phases as shown in Figure 42: contact

867 adjustment, elastic branch, strain hardening and strain softening phases. First, at the early stages of loading, the soil and fibre particles are gradually redistributed to fill the voids that exist in 
the composite until a steady state is reached. Second, the elastic linear part of the stress-strain occurred where no cracks were experimentally observed. Third, the progress of compression load leads to noticeable increase of the stress-strain curve. In this phase, multiple splitting cracks start developing. However, brick samples still resist loads, until the maximum stress is reached. Finally, as the strain increases, cracks develop in uncontrolled way and crack width increases due to localization of damage until failure (the ultimate normalised strain is reached). Barrelling shape deformation can be observed in this phase.

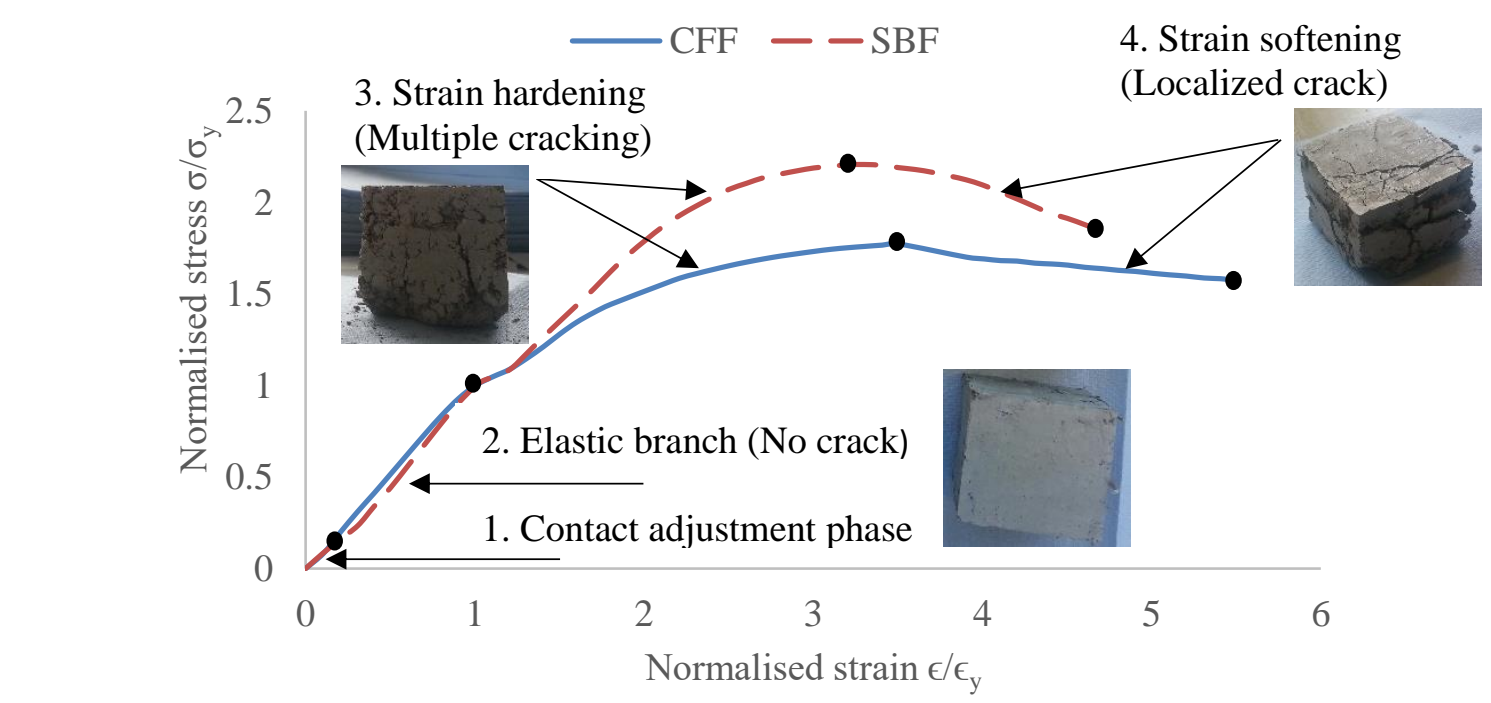

Figure 42: Typical normalised stress-strain curves for natural fibre reinforced soil bricks.

All constitutive models presented in this study contributes to knowledge of the behaviour of natural fibre reinforced soil bricks. Such models are important for finite element modelling of fibre reinforced soil bricks.

The only variable of fibre reinforced soil bricks that is not covered by proposed models in this study is the random distribution and orientation of the fibre in the mix. Detailed micro finite element modelling is currently underway to investigate this. 
892

This study presents properties and constitutive relationships of natural fibre reinforced soil bricks. Based on the experimental investigation reported in this study, the following conclusions are drawn:

1. Compressive and tensile strength of the soil bricks increases with increase in the length for both types of fibre up to certain length. In this study, the optimum fibre length recorded is $15 \mathrm{~mm}$ for both compressive and tensile strengths.

2. Experimental investigation revealed an improvement in mechanical properties of natural fibre reinforced soil bricks compared to unreinforced soil bricks. For example, CFF and SBF improved the bending tensile strength compared to bricks without reinforcement fibres. Addition of 7\% CFF resulted in a $98.8 \%$ increase in compressive strength and $97.4 \%$ increase in tensile strength at 14 days. At 5\% SBF, both compressive strength and bending tensile strengths were improved by $78.7 \%$ and $65.0 \%$ respectively at 14 days. These values meet the British specification for soil bricks. CFF reinforced soil bricks showed slightly more improvement in compression than those reinforced with SBF.

3. The optimum quantity of fibre for compressive and tensile strength, in this study is, $7 \%$ for CFF and 5\% for SBF at an optimum fibre length of $15 \mathrm{~mm}$.

4. The results revealed that reinforced samples with CFF or SBF are acceptable and suitable for use as a building material according to the required standards.

5. Simple empirical equations along with Response Surface models and stress-strain relations were developed to express and predict key information about the behaviour of fibre reinforced soil bricks. These models are useful for future analytical and numerical computations of natural fibre reinforced earth structures. 
The results obtained show that there is potential for the use of CFF and SBF in reinforced soil

916 bricks. The resulting bricks will be affordable and lightweight construction materials with

917 satisfactory mechanical performance. All these characteristics encourage the commercial

918 production of soil bricks with natural fibres on a large scale, especially for affordable housing

919 construction in developing countries.

\section{Declarations of interest}

921 None.

\section{ACKNOWLEDGMENT}

923 The authors gratefully acknowledge the research support fund provided by the Sudanese

924 Ministry of Higher Education, School of Engineering University of Khartoum and the School

925 of Engineering, University of Aberdeen.

\section{References}

[1] Chan C. Effect of natural fibres inclusion in clay bricks: Physico-mechanical properties. International Journal of Civil, Environmental, Structural, Construction and Architectural Engineering 2011;5(1): 7-13.

[2] Coffman R, Agnew N, Auiston G, Doehne E. Adobe mineralogy: characterization of adobes from around the world. In: Adobe 90 preprints, Proceedings of the $6^{\text {th }}$ International Conference on the Conservation of Earthen Architecture, New Mexico, 14-19 October 1990. P. 424-429.

[3] Eliche-Quesada D, Felipe-Sesé MA, López-Pérez JA, Infantes-Molina A. Characterization and Evaluation of Rice Husk Ash and Wood Ash in Sustainable Clay Matrix Bricks. Ceramics International 2016;43(1): 463-475.

https://doi.org/10.1016/j.ceramint.2016.09.181. 
[4] Görhan G, Şimşek O. Porous Clay Bricks Manufactured with Rice Husks. Construction and Building Materials 2013;40: 390-396.

https://doi.org/10.1016/j.conbuildmat.2012.09.110.

[5] Salih MM, Osofero AI, Imbabi MS. Critical Review of Recent Development in Fibre Reinforced Adobe Bricks for Sustainable Construction. Frontiers of Structural and Civil Engineering (Accepted/In press, 11 July 2019).

[6] Nkayem N, Mbey J, Kenne B, Njopwouo D. Preliminary Study on the Use of Corn Cob as Pore Forming Agent in Lightweight Clay Bricks: Physical and Mechanical Features. Journal of Building Engineering 2016;5: 254-259.

https://doi.org/10.1016/j.jobe.2016.01.006.

[7] Aymerich F, Fenu L, Meloni P. Effect of Reinforcing Wool Fibers on Fracture and Energym Absorption Properties of an Earthen Material. Construction and Building Materials 2012;27(1): 66-72. https://doi.org/10.1016/j.conbuildmat.2011.08.008.

[8] Bock-Hyeng C, Ofori-Boadu A, Yamb-Bell E, Shofoluwe M. Sugarcane FiberReinforced Bricks as a Sustainable Construction Material. In: Proceedings of the 2016 IAJC-ISAM Joint International Conference, California, 6-8 November 2016. P. 379388.

[9] Vega P, Juan A, Guerra MI, Morán JM, Aguado PJ, Llamas B. Mechanical characterisation of traditional adobes from the north of Spain. Construction and Building Materials 2011;25(7): 3020-3023.

https://doi.org/10.1016/j.conbuildmat.2011.02.003.

[10] Rojas-Valencia MN, Bolaños EA. Sustainable adobe bricks with construction wastes. Waste and Resource Management 2016;169(4): 158-165.

https://doi.org/10.1680/jwarm.16.00014. 
[11] Taallah B, Guettala A, Guettala S, Kriker A. Mechanical properties and hygroscopicity behavior of compressed earth block filled by date palm fibers. Construction and Building Materials 2014;59: 161-168.

https://doi.org/10.1016/j.conbuildmat.2014.02.058.

[12] El-Mahllawy MS, Kandeel AM. Engineering and mineralogical characteristics of stabilized unfired montmorillonitic clay bricks. HBRC Journal 2014;10(1): 82-91. https://doi.org/10.1016/j.hbrcj.2013.08.009.

[13] Binici H, Aksogan O, Shah T. Investigation of fibre reinforced mud brick as a building material. Construction and Building Materials 2005;19(4): 313-318. https://doi.org/10.1016/j.conbuildmat.2004.07.013.

[14] Taallah B, Guettala A. Mechanical and physical properties of compressed earth block stabilized with lime and filled with untreated and alkali-treated date palm fibers. Construction and Building Materials 2016;104: 52-62.

https://doi.org/10.1016/j.conbuildmat.2015.12.007.

[15] Demir I. An Investigation on the Production of Construction Brick with Processed Waste Tea. Building and Environment 2006;41(9): 1274-1278. https://doi.org/10.1016/j.buildenv.2005.05.004.

[16] Galán-Marín C, Rivera-Gómez C, Petric J. Clay-based composite stabilized with natural polymer and fibre. Construction and Building Materials 2010;24(8): 14621468. https://doi.org/10.1016/j.conbuildmat.2010.01.008.

[17] Zhan M, Wool RP. Mechanical Properties of Chicken Feather Fibers. Polymer Composites 2011;32: 938-944. https://doi.org/10.1002/pc.21112.

[18] Reddy N, Chen L, Zhang Y, Yang Y. Reducing Environmental Pollution of the Textile Industry Using Keratin as Alternative Sizing Agent to Poly(vinyl alcohol). Journal of Cleaner Production 2014;65: 561-567.https://doi.org/10.1016/j.jclepro.2013.09.046. 
[19] Roh MS, Bauchan GR, Huda MS. The Effect of Biobased Plastic Resins Containing Chicken Feather Fibers on the Growth and Flowering of Begonia Boliviensis. Horticulture, Environment, and Biotechnology 2012;53(1): 81-89.

https://doi.org/10.1007/s13580-012-0118-z.

[20] Al-Asheh S, Banat F. Beneficial Reuse of Chicken Feathers in Removal of Heavy Metals from Wastewater. Journal of Cleaner Production 2003;11(3): 321-326. https://doi.org/10.1016/S0959-6526(02)00045-8.

[21] Salih MM, Osofero AI, Imbabi MS. Mechanical Properties of Fibre-reinforced mud bricks. In: Proceedings of the $2{ }^{\text {nd }}$ Conference on Civil Engineering (Sudan), Khartoum, 3-5 December 2018. P. 91-96.

[22] Sun XF, Sun RC, Sun JX. Acetylation of Sugarcane Bagasse Using NBS as a Catalyst Under Mild Reaction Conditions for the Production of Oil Sorption Active Materials. Bioresource Technology 2004;95(3): 343-350.

https://doi.org/10.1016/j.biortech.2004.02.025.

[23] Abdul Kadir A, Maasom N. Recycling Sugarcane Bagasse Waste into Fired Clay Brick. International Journal of Zero Waste Generation 2013;1(1): 21-26.

[24] Vieira CMF, Borlini MC, Monteiro SN. Incorporation of Ash from Sugarcane Bagasse into Clay Bricks. Industrial Ceramics 2006;25(2): 23-29.

[25] Teixeira SR, Souza AE, Santos GTA, Pena AFV. Sugarcane Bagasse Ash as a Potential Quartz Replacement in Red Ceramic. Journal of the American Ceramic Society 2008;91(6): 1883-1887. https://doi.org/10.1111/j.1551-2916.2007.02212.x.

[26] ASTM, Standard Test Method for Particle-Size Analysis of Soils, Historical Standard, Developed by Subcommittee: D422-2007, v2; 2007.

[27] ASTM, Standard Test Methods for Mechanical Properties of Lumber and Wood-Base Structural Material Developed by Subcommittee: D4761-2013, 2013. 
[28] British Standard EN 1052-2, Methods of Test for Masonry units. Determination of Compressive Strength, BSI, London, 2016.

[29] British Standard EN 772-13, Methods of Test for Masonry Units Part 13: Determination of Net and Gross Dry Density of Masonry Units (Except for Natural Stone), BSI, London, 2000.

[30] Weng C-H., Lin DF, Chiang, PC. Utilization of sludge as brick materials. Advances in Environmental Research 2003;7: 679-685.

https://doi.org/10.1016/S1093-0191(02)00037-0.

[31] British Standard EN 771-1, Specification for Masonry Units — Part 1: Clay Masonry Units, BSI, London, 2003.

[32] British Standard EN 1015-11. Methods of test for mortar for masonry -part 11: determination of flexural and compressive strength of hardened mortar, Brussels, Comité Européen de Normalisation, v11; 1999.

[33] Zhang L. Production of bricks from waste materials: a review. Construction and Building Materials 2013;47: 643-55.

https://doi.org/10.1016/j.conbuildmat.2013.05.043.

[34] Velasco PM, Ortíz MP, Giró MA, Velasco LM. Fired clay bricks manufactured by adding wastes as sustainable construction material - A review. Construction and Building Materials 2014;63: 97-107.

https://doi.org/10.1016/j.conbuildmat.2014.03.045.

[35] Sharma V, Marwaha BM, Vinayak HK. Enhancing durability of adobe by natural reinforcement for propagating sustainable mud housing. International Journal of Sustainable Built Environment, 2016;5: 141-155.

https://doi.org/10.1016/j.ijsbe.2016.03.004. 
[36] Zak P, Ashour T, Korjenic A, Korjenic S, Wu W. The influence of natural reinforcement fibers, gypsum and cementon compressive strength of earth bricks materials. Construction and building Materials, 2016;106: 179-188.

https://doi.org/10.1016/j.conbuildmat.2015.12.031.

[37] ASTM C20-00, Standard Test Methods for Apparent Porosity, Water Absorption, Apparent Specific Gravity, and Bulk Density of Burned Refractory Brick and Shapes by Boiling Water, ASTM International, West Conshohocken, PA, 2015.

[38] Donkor P, Obonyo E. Compressed soil blocks: Influence of fibers on flexural properties and failure mechanism. Construction and Building Materials, 2016;121: 25-33.

https://doi.org/10.1016/j.conbuildmat.2016.05.151.

[39] Danso H, Martinson DB, Ali M, Williams J. Effect of fibre aspect ratio on mechanical properties of soil building blocks. Construction and Building Materials, 2015;83: 314 319. https://doi.org/10.1016/j.conbuildmat.2015.03.039.

[40] Turkish Standard Institution TS 2514. Adobe blocks and production methods; 1977.

[41] New Mexico Construction Bureau, New Mexico Adobe and Rammed Earth Building Code, Construction Industries Division, General Construction Bureau, New Mexico, 2009.

[42] Morel JC, Pkla A, Walker P. Compressive strength testing of compressed earth blocks. Construction and Building Materials 2007;21(2): 303-309. https://doi.org/10.1016/j.conbuildmat.2005.08.021.

[43] Serrano S, Barreneche C, Cabeza LF. Use of by-products as additives in adobe bricks: Mechanical properties characterisation. Construction and Building Materials, 2016; 108: 105-111. https://doi.org/10.1016/j.conbuildmat.2016.01.044. 
[44] Calatan G, Hegyi A, Dico C, Mircea C. Determining the optimum addition of vegetable materials in adobe bricks. Procedia Technology, 2016;22: 259-265.

https://doi.org/10.1016/j.protcy.2016.01.077.

[45] Subramaniaprasad CK, Abraham BM, and Nambiar EK. Influence of Embedded Waste-Plastic Fibers on the Improvement of the Tensile Strength of Stabilized Mud Masonry Blocks. Journal of Materials in Civil Engineering, 2015;27: 1-7. https://doi.org/10.1061/(ASCE)MT.1943-5533.0001165.

[46] Oliver M, Gharbi ZEl. Sisal fiber reinforced soil block masonry. In: British Masonry Society, Proceedings of the $4^{\text {th }}$ International Masonry Conference, London, 1995. P. $55-58$.

[47] Momoh EO, Osofero AI. Behaviour of oil palm broom fibres (OPBF) reinforced concrete. Construction and Building Materials, 2019; 221: 745-761. https://doi.org/10.1016/j.conbuildmat.2019.06.118.

[48] Parisi F, Asprone D, Fenu L, Prota A. Experimental characterization of Italian composite adobe bricks reinforced with straw fibers. Composite Structures, 2015;122: 300-307. https://doi.org/10.1016/j.compstruct.2014.11.060. 